\title{
A Bridge not too Far: Personalized Medicine with the use of Theragnostic Radiopharmaceuticals
}

\author{
Suresh C Srivastava
}

\begin{abstract}
This article deals primarily with the selection criteria, production, and the nuclear, physical, and chemical properties of certain dual-purpose radionuclides, including those that are currently being used, or studied and evaluated, and those that warrant future investigations. Various scientific and practical issues related to the production and availability of these radionuclides is briefly addressed. At brookhaven national laboratory (BNL), we have developed a paradigm that involves specific individual 'dual-purpose' radionuclides or radionuclide pairs with emissions suitable for both imaging and therapy, and which when molecularly (selectively) targeted using appropriate carriers, would allow pre-therapy low-dose imaging plus higher-dose therapy in the same patient. We have made an attempt to sort out and organize a number of such theragnostic radionuclides and radionuclide pairs that may thus potentially bring us closer to the age-long dream of personalized medicine for performing tailored low-dose molecular imaging (SPECT/CT or PET/CT) to provide the necessary pretherapy information on biodistribution, dosimetry, the limiting or critical organ or tissue, and the maximum tolerated dose (MTD), etc., followed by performing higher-dose targeted molecular therapy in the same patient with the same radiopharmaceutical. As an example, our preclinical and clinical studies with the theragnostic radionuclide $\mathrm{Sn}-117 \mathrm{~m}$ are covered in somewhat greater detail.

A troublesome problem that remains yet to be fully resolved is the lack of availability, in sufficient quantities and at reasonable cost, of a majority of the best candidate theragnostic radionuclides in a no-carrier-added (NCA) form. In this regard, a summary description of recently developed new or modified methods at BNL for the production of five theragnostic radionuclide/radionuclide pair items, whose nuclear, physical, and chemical characteristics seem to show promise for therapeutic oncology and for treating other disorders that respond to radionuclide therapy, is provided.
\end{abstract}

Keywords: Radionuclide therapy, Personalized medicine, Theragnostics, Theragnostic radiopharmaceuticals, Tin-117m, Radionuclide production, Cancer therapy, Cardiovascular therapy.

How to cite this article: Srivastava SC. A Bridge not too Far: Personalized Medicine with the use of Theragnostic Radiopharmaceuticals. J Postgrad Med Edu Res 2013;47(1): 31-46.

\section{Source of support $\mathrm{Nil}$}

Conflict of interest: None declared

\section{INTRODUCTION}

Nuclear medicine has experienced an exponential resurgence of interest in radiotherapeutic procedures. U sing unsealed sources for radionuclide therapy is not a new concept; it has been around for over 5 decades starting with the development of among others the treatment of thyroid disorders with radioiodine. However, recent advances in molecular biology have led to a better understanding of cancer and other disease states, and parallel research has shown promise for biological vehicles, such as monoclonal antibodies, specific proteins and peptides, and a variety of other intelligently designed molecules, to serve as specific carriers to deliver cell killing radiation into tumors in a highly localized fashion. These devel opments have led to a renewed interest in the exciting possibility of treating human malignancies with the systemic administration of radionuclides. A number of other relatively new modalities, such as the treatment of metastatic bone pain, radiation synovectomy, bone marrow ablation, and others, have given additional impetus to need for research on therapeutic radionuclides tailored for specific applications.

A major advantage of radionuclides is that they emit radiation of different radiobiological effectiveness and range of action. This offers the possibility of choosing a nuclide the physical and nuclear characteristics of which are matched with a particular tumor type, or the disease under treatment. In addition, certain dual-purpose ('theragnostic') radionuclides that seem to offer the exciting potential of pretherapy low dose imaging followed by higher dose treatment in the same patient, thus possibly bringing us a major step closer to personalized medicine, are discussed in somewhat greater detail in this article. We are reintroducing and reinforcing this relatively novel paradigm that involves specific individual theragnostic radionuclides or radionuclide pairs with emissions suitable for both imaging and therapy, and which when molecularly (selectively) targeted using appropriate carriers, would allow pretherapy low dose imaging plus higher dose therapy in the same patient. W e have made an attempt to sort out and organize a number of such theragnostic radionuclides and radionuclide pairs that may thus potentially bring us a major step closer to the age-long dream of personalized medicine for performing tailored low dose molecular imaging (SPECT/CT or PET/CT) to provide the necessary pretherapy information on biodistribution, dosimetry, the limiting or critical organ or tissue, and the maximum tolerated dose (M TD), etc. followed by performing higher dose targeted molecular therapy in the same patient with the same radiopharmaceutical. B eginning in the 1980 's, our work at 
Brookhaven National L aboratory (BNL) with such a 'dualpurpose' radionuclide, tin- $117 \mathrm{~m}$, convinced us that it is arguably one of the most promising theragnostic radionuclides and we have continued to concentrate on this effort. Our results with this radionuclide are therefore covered in somewhat greater detail in this paper.

\section{THERAGNOSTIC RADIONUCLIDES}

As mentioned above, certain radionuclides or radionuclide pairs have emissions that allow pretherapy information with low dose imaging, followed by higher dose therapy in the same patient. ${ }^{1-4}$ Such dual-purpose theragnostic radionuclides, for example I-131, or the pair I-124/I-131 have been around and used for imaging followed by therapy, without consideration to the fact that the optimum radionuclide or the optimum radionuclide pair were not scientifically or methodically chosen with this requirement and/or with the particular disease in mind. Over 2 decades ago, when $Y-90$ began to be promoted for radioimmunotherapy and was undergoing rapid development, it was considered necessary to use In-111-monoclonal antibody ( $\mathrm{mA}$ b) as a surrogate to carry out biodistribution and imaging studies in order to predict the dosimetry and toxicity prior to doing the therapy with $\mathrm{Y}-90-\mathrm{mA}$, because of the lack of imageable photons in $Y-90$ emissions. A fter some very careful studies, the Julich group ${ }^{5}$ and our own group at B rookhaven ${ }^{6,7}$ showed that at best, it was hazardous to do so because these were two different elements whose biochemistry had many similarities but also many striking dissimilarities as well. Interestingly, this practice still continues, because of the lack of an alternate solution. ${ }^{8}$ In such a situation, it would have been best to use the positron emitter $Y-86$, a congener of $Y-90$, and therefore with the same chemical and biochemical properties, to carry out pretherapy positron emission tomography (PET) imaging, so that imaging predicts biodistribution and dosimetry in a reliable, individualized fashion, and thus also predicts as to which patients will respond to the radionuclide therapy with Y -90 and which will not. However, Y -86 until very recently has not been available at all or only in insufficient quantities for this purpose. This situation is now changing and in many cases, if the therapeutic isotope has no photon emission, suitable congeners for imaging are becoming more and more available.

It is noteworthy that a number of such radionuclides or radionuclide pairs do exist ${ }^{1-4}$ and it would make a lot of sense to direct their use for the development of 'theragnostic radiopharmaceuticals' . It is important to stress that ideally, for theragnostic use, the molecularly targeted radiopharmaceutical should constitute the same dual-purpose radionuclide with both imaging and therapeutic emissions. In the second best situation, as mentioned above for the Y -90 situation, a radionuclide pair (imaging photon emitter, either gamma or positron, and a congener of the therapeutic particle emitter, with the same electronic structure) can be used as well. One caveat here, which is a fact of life, is that even though many theragnostic PET/therapy radionuclide pairs may have the same electronic structure, their production and processing methodologies may be significantly different leading to the fact that their chemistry and in vivo behavior may be different as well due to differences in chemical species, charge, specific activity, etc. and/or the amount of chemical and radionuclidic and chemical impurities, which cannot be totally removed. A nother caveat that one has to deal with is the issue of halflife of the imaging PET congener which in most cases might be much shorter than the usually (desirable) longer halflife of the therapeutic congener. In most situations, the determination of longer term biodistribution and dosimetry would be crucial but this information would not be achievable using the shorter lived PET congener for pretherapy imaging.

To re-emphasize, the theragnostic radionuclides or radionuclide pairs would initially allow molecular imaging (SPECT/CT or PET/CT) to provide the required and useful pretherapy information on biodistribution, dosimetry, the limiting or critical organ or tissue, and the maximum tolerated dose (MTD). If the imaging results then warrant it, it would be safe and appropriate to follow-up with dose ranging experiments to allow higher dose targeted molecular therapy with the greatest effectiveness. These factors are especially important in order to be able to do tailored imaging plus therapy (personalized medicine) in the same patient with the same radiopharmaceutical. ${ }^{1-4}$

There are indeed a number of individual radionuclides that emit both imaging photons and therapeutic electrons and which would be potentially excellent choices for theragnostic applications (Table 1). Some of the most promising PET/therapy radionuclide pairs are shown in Table 2. The lists included in both Tables 1 and 2 are not all-inclusive but consist of selected radionuclides and radionuclide pairs that are or could be made available in sufficient quantities to be of practical value, and which show the required combination of nuclear, physical and chemical properties, and thus the greatest promise. Some other criteria for inclusion were arbitrarily set at a minimum of $20 \%$ photon/positron emission for imaging, and a sufficiently abundant therapeutic particle emission consisting of medium $\left(\beta^{-}\right)$to high linear energy transfer (LET) electrons. It should be noted that there may be other suitable candidates from 
A Bridge not too Far: Personalized Medicine with the use of Theragnostic Radiopharmaceuticals

\begin{tabular}{|c|c|c|c|}
\hline Radionuclide & $\mathrm{t}^{1} / 2$ (days) & $\begin{array}{l}\text { Principal y energy for } \\
\text { imaging, } \mathrm{keV}(\%)\end{array}$ & $\begin{array}{l}\text { Therapeutic particle(s) [Avg energy, } \\
\text { keV (\%) abundance] }\end{array}$ \\
\hline Scandium-47 & 3.35 & $159(68)$ & $\beta-(162)$ \\
\hline Copper-67 & 2.58 & $186(40$ & $\beta-(141)$ \\
\hline Gallium-67 & 3.26 & $\begin{array}{l}93.184,296 \\
(40,24,22)\end{array}$ & $\begin{array}{l}15 \text { Auger, } 0.04-9.5 \mathrm{keV}, 572 \% \\
10 \mathrm{CE}, 82-291 \mathrm{keV}, 30 \%\end{array}$ \\
\hline Indium-111 & 2.80 & $171,245(91,94)$ & $\begin{array}{l}6 \text { Auger, } 0.13-25.6 \mathrm{keV}, 407 \% \\
12 \mathrm{CE}, 144-245 \mathrm{keV}, 21 \%\end{array}$ \\
\hline Tin-117m & 14.00 & $159(86)$ & 8 CE (141 keV avg, $114 \%)$ \\
\hline lodine-123 & $13.3 \mathrm{~h}$ & $159(83)$ & $\begin{array}{l}12 \text { Auger, } 23-30.4 \mathrm{keV}, 1371 \% \\
7 \mathrm{CE}, 0.014-32 \mathrm{keV}, 17 \%\end{array}$ \\
\hline lodine-131 & 8.0 & $365(82)$ & $\beta-(181)$ \\
\hline Samarium-153 & 1.94 & $103(30)$ & $\beta-(280)$ \\
\hline Astatine-211 & $7.2 \mathrm{~h}$ & $79(21)$ & $\alpha(5867,42 \%)$ \\
\hline B ismuth- 213 & $46 \mathrm{~min}$ & $441(926)$ & $\begin{array}{l}\beta \text {-(425); } \alpha(98 \%, \text { from } \mathrm{Tl}-209 \\
\text { daughter, } 2 \% \text { from } \mathrm{Bi}-213)\end{array}$ \\
\hline
\end{tabular}

\begin{tabular}{|c|c|c|c|}
\hline $\begin{array}{l}\text { Radionuclide pair } \\
\text { imaging/therapeutic }\end{array}$ & $\mathrm{T}^{1 / 2}(\mathrm{~d})$ & Imaging positron, keV (\%) & $\begin{array}{l}\text { Therapeutic particle(s) } \\
\text { (avg energy, keV) }\end{array}$ \\
\hline Scandium-44/scandium-47 & $3.97 / 3.35$ & $y \pm 511(99.9 \%)$ & $\beta-(162)$ \\
\hline Copper-64/copper-67 & $0.53 / 2.6$ & $y \pm 511(38 \%)$ & $\beta-(141)$ \\
\hline Gallium-68/gallium-67 & $68 \mathrm{mins} / 3.26$ & $y \pm 511(176 \%)$ & $\begin{array}{l}15 \text { Auger, } 0.04-9.5 \mathrm{keV}, 572 \% 10 \mathrm{CE} \\
82-291 \mathrm{keV}, 30 \%\end{array}$ \\
\hline Yttrium-86/yttrium-90 & $0.61 / 2.7$ & $y \pm 511(35 \%)$ & $\beta-(935)$ \\
\hline lodine-124/iodine-131 & $4.2 / 8.0$ & $y \pm 511(38 \%)$ & $\beta-(181) \mathrm{i} / \mathrm{mg}$ of ${ }^{67} \mathrm{Zn}(\mathrm{mb})$ \\
\hline
\end{tabular}

the class of alpha and A uger electron emitters, ${ }^{1-4,9-11}$ but these have not been included in this theragnostic group of radionuclides (except $\mathrm{A}$ C-225/Bi-213) since their availability is either limited or not enough preclinical and clinical experimental data have thus far been available.

As mentioned above, a major problem that remains yet to be completely resolved is the lack of availability of a number of the best candidate therapeutic radionuclides, in particular the theragnostic radionuclides or PET/SPECT radionuclide pairs, in sufficient quantities and/or in a nocarrier-added (NCA) form. M ethods have already been studied and developed for the production of research quantities of certain theragnostic radionuclides and radionuclide pairs listed in Tables 1 and 2 in particul ar $\mathrm{Cu}$ $64,{ }^{12} Y-86,{ }^{1-4,13,14} \mid-124,{ }^{15}$ and Sc-44. ${ }^{16}$ Gallium-67, Y -90, In-111, I-123, Sm-153, Lu-177 and I-131 are routinely available from commercial sources. Close to sufficient quantities of $\mathrm{Ge}-68$ (parent of $\mathrm{Ga}-68$ ) are made available mainly from the B rookhaven L inac Isotope Producer (BLIP) at B rookhaven National L aboratory (BNL) ${ }^{17}$ and from the Isotope Production Facility (IPF) at Los A lamos National Laboratory (LANL).

A summary description relating to the development of new or modified methods for the production of selected promising theragnostic radionuclides (Sc-47, Cu-67, Y -86, Sn-117m and A C-225/Bi-213) is included in the following sections. Some of these have undergone through various stages of preclinical/clinical trials.

\section{PRODUCTION OF SELECTED THERAGNOSTIC RADIONUCLIDES}

\section{Beta Emitters}

\section{Scandium-47}

Two low energy reactions in the reactor that produce NCA Sc-47 are ${ }^{47} \mathrm{Ti}-47(\mathrm{n}, \mathrm{p}){ }^{47} \mathrm{Sc}$ and ${ }^{46} \mathrm{Ca}(\mathrm{n}, \gamma){ }^{47} \mathrm{Ca}\left(\beta^{-}\right)\left(\mathrm{t}^{1 / 2} / 2=\right.$ 4.54 days). ${ }^{18}$ The former reaction requires $E_{n}>1 \mathrm{M} \mathrm{eV}$, while the latter reaction uses thermal neutrons. Both types of neutrons are available in the fission neutron spectrum in the High Flux Isotope Reactor at $\mathrm{O}$ ak Ridge $\mathrm{National}$ Laboratory. The advantages of the ${ }^{46} \mathrm{Ca}(\mathrm{n}, \gamma){ }^{47} \mathrm{Ca}\left(\beta^{-}\right)$ reaction are: (i) The year-round availability of high flux thermal neutrons and (ii) use of a $\mathrm{Ca}-47 / \mathrm{Sc}-47$ generator system to supply Sc-47 activity. The disadvantage of this route is the requirement of an enriched target. Calcium- 46 is presently available with only $30 \%$ enrichment and at a very high price, which makes target costs prohibitive.

The ${ }^{47} \mathrm{Ti}(\mathrm{n}, \mathrm{p})$ route al so requires an enriched target though ${ }^{47} \mathrm{Ti}^{-} \mathrm{O}_{2}$ is available with very high enrichment $(94.53 \% \mathrm{Ti}$ 47, 4.74\% Ti-48, 0.35\% Ti-46, 0.2\% Ti-49 and 0.18\% Ti50) and at more reasonable cost. The hydraulic tube positions at HFIR at ORNL (with $4.6 \times 10^{14}$ neutrons $/ \mathrm{cm}^{2}$ s) have 
adequate flux in the high energy region of the neutron spectra to produce sufficient quantities of Sc-47 activity for theragnostic applications in radioimmunotherapy. The reported cross-section in a fission neutron spectrum is 18.926 mbarn, which is comparable to the cross-section value for proton-induced reactions, such as ${ }^{\text {nat }} \mathrm{Ti}(\mathrm{p}, 2 \mathrm{p})$ and ${ }^{51} \mathrm{~V}(\mathrm{p}$, $3 p n)^{19}$

Several ${ }^{47} \mathrm{TiO}_{2}$ targets were irradiated at HFIR for periods ranging from a few hours to several days. ${ }^{19}$ The experimental results are lower than the theoretical ones, perhaps due to differences in the actual neutron spectrum when the irradiations occurred compared to the theoretical neutron spectrum. High production yields using the PTP positions at the HFIR were obtained. These results indicate that Sc-47 can be produced at a reactor using the ${ }^{47} \mathrm{Ti}(\mathrm{n}, \mathrm{p})$ reaction in quantities sufficient for theragnostic applications. For example, at HFIR a 3.35 day (one half-life of Sc-47) irradiation of a $10 \mathrm{~g}$ target would theoretically produce $\sim 75 \mathrm{Ci}$ of Sc-47 at EOB. B oth the Sc-46/Sc-47 and Sc-48/ Sc-47 impurity ratios are less than $0.4 \%$ at EOB (end of bombardment), leading to a product with greater than $99.5 \%$ radiopurity. ${ }^{18,19}$

The specific activity of Sc-47 depends essentially on the scandium content of the enriched target material. Scandium is not a ubiquitous contaminant, such as lead or copper, and would not be expected to be introduced during processing of the target. These expectations were borne out when several product samples were analyzed with ICP-A E and no stable Sc was detected. ${ }^{19}$ Since scandium was not detected in batches of target material, stable scandium content can be assumed to be the reported detection limit. The specific activities are high enough for antibody labeling applications in radioimmunotherapy. Conservatively assuming that an average of two to three scandium-ligand complexes can be attached to each antibody molecule without loss of immunoreactivity, up to $30 \mathrm{mCi}(1.16 \mathrm{~GB} \mathrm{q})$ of ORNL produced Sc-47 can be used to label $1 \mathrm{mg}$ of a typical IgG antibody (mol. wt. 150 kDa) given the measured specific activities. ${ }^{19}$
Finally, it is necessary to recycle the expensive enriched target material to defray the target cost over many production runs. A simple procedure was developed that recovers $\sim 98.5 \%$ of the oxide based on precipitation of titanium at basic $\mathrm{pH}$ followed by conversion to the oxide using higher temperature. ${ }^{19}$ Titanium may be recovered and easily reused since the only titanium activation product is the short lived $\mathrm{Ti}-51$ ( $\mathrm{t}^{1} \mathrm{2} / 2=5.8$ minutes) produced by the ${ }^{50} \mathrm{Ti}(\mathrm{n}, \gamma)$ reaction using thermal neutrons. 0 ther radionuclidic impurities that have been detected in recycled material are Ta-182 ( $\mathrm{t}^{1} / 2=$ 114.4 days) and $\mathrm{Zn}-65\left(\mathrm{t} 1 \frac{1}{2}=244\right.$ days). These isotopes are also produced by $(n, \gamma)$ reactions on minor target impurities of stable Ta and $\mathrm{Zn}$. If required, these impurities could easily be separated from the target material using anion-exchange chromatography before precipitation of the titanium. ${ }^{19}$

Relative production yields were also determined using the $(\mathrm{p}, 2 \mathrm{n})$ reaction on ${ }^{48} \mathrm{TiO}_{2}$ targets $\left(98.5 \%{ }^{48} \mathrm{TiO}_{2}\right)$ at the $B L I P$ in the energy region $48<E_{p}<150 \mathrm{M} \mathrm{eV} .18,19$ These targets were irradiated to see whether the use of isotopically enriched Ti-48 would improve the Sc-47/Sc-44m, 46,48 radioimpurity ratios compared to using natural $\mathrm{Ti}$ targets. There is the expected improvement in the Sc- $47 / \mathrm{Sc}-44$ ratios using enriched targets since the ${ }^{49} \mathrm{Ti}(p, 2 p)^{48} \mathrm{Sc}$ and ${ }^{50} \mathrm{Ti}(\mathrm{p}$, $2 \mathrm{pn})^{48} \mathrm{Sc}$ reaction pathways have been eliminated. The Sc-47/Sc- $44 \mathrm{~m}$ ratio is better at lower irradiation energies $(\mathrm{Ep}<100 \mathrm{M} \mathrm{eV})$; however, unfortunately the Sc-47/Sc-46 ratios are worse throughout the energy region measured. Thus, this production method would not be suitable for producing Sc-47 with sufficient purity for therapeutic use. ${ }^{19}$

Although Cu- 67 has long been considered as one of the ideal therapeutic/theragnostic radionuclides (vide infra), its scaled up production with a sufficiently high specific activity is still an issue that has only partially been resolved and further improvements are difficult if not questionable, at this time. With this in mind, we have proposed Sc-47 as a possible replacement for $\mathrm{Cu}-67^{20}$ as shown in Table 3.

\begin{tabular}{|c|c|c|c|c|}
\hline & \multicolumn{2}{|c|}{ Cu-67 } & \multicolumn{2}{|c|}{ Sc-47 } \\
\hline & Advantages & Disadvantages & Advantages & Disadvantages \\
\hline Half-life & $\begin{array}{l}\text { Good } \\
(2.58 \mathrm{~d})\end{array}$ & - & $\begin{array}{l}\text { Good } \\
(3.35 d)\end{array}$ & - \\
\hline $\begin{array}{l}\text { Beta energy, keV } \\
\text { (total, weighted avg.) }\end{array}$ & $\begin{array}{l}\text { Good } \\
\text { (141) }\end{array}$ & - & $\begin{array}{l}\text { Good } \\
\text { (163) }\end{array}$ & - \\
\hline Imageable photon (keV, \%) & $\begin{array}{l}\text { Good } \\
(185,49 \%)\end{array}$ & - & $\begin{array}{l}\text { Good } \\
(159,68 \%)\end{array}$ & - \\
\hline Specific activity & - & $\begin{array}{l}\text { Low } \\
(2-18 \mathrm{mCi} / \mu \mathrm{g})\end{array}$ & $\begin{array}{l}\text { High } \\
\text { (no-carrier added) }\end{array}$ & - \\
\hline Radiochemistry & - & Average & Good & - \\
\hline Ease of production & - & Hard (accelerator) & Easy (reactor) & \\
\hline
\end{tabular}




\section{Copper-67}

Copper-67, with a 2.6-day half-life, is the longest lived radioisotope of $\mathrm{Cu}^{21} \mathrm{It}$ provides medium energy emission of $0.6 \mathrm{MeV}_{\max }$ (average, $141 \mathrm{keV}$ ), photon emissions (184 keV, 48.7\%; $93 \mathrm{keV}, 16 \%$; $91 \mathrm{keV}, 7 \%$ ), and facile labeling chemistry. It is a very attractive theragnostic radionuclide. ${ }^{1-4}$ The half-life is suitable for imaging slow in vivo pharmacokinetics with agents, such as mA bs and other carrier molecules, and the beta particle energy is appropriate for therapy. The $185-\mathrm{keV}$ gamma ray $(49 \%)$ permits imaging of the uptake and biodistribution of the agent both before and during therapy administration. It can also be paired with the positron emitter $\mathrm{Cu}-64$ to perform pretherapy biodistribution determinations and dosimetry by PET. However, as mentioned earlier in this article, the use of $\mathrm{Cu}-67$ has been inhibited by a lack of regular availability of sufficient quantities at a cost that researchers can typically afford, as well as the low specific activity issue. ${ }^{7,21}$ In the past several decades, the most typical source in the U nited States has been the high energy proton irradiation of natural $\mathrm{Zn}$ targets, ${ }^{21}$ primarily irradiated at either the BLIP (B rookhaven Linac Isotope Producer) at BNL or at the Isotope Production Facility (IPF) at LANL (Los A lamos National Laboratory). These are both large accelerators operated and funded for physics research only part of each year. Thus, in the past, it has not been possible to provide Cu-67 on a time frame suitable to support clinical trials, with the attendant schedule fluctuations and changing patient status. ${ }^{22,23} \mathrm{~A}$ dditionally, the specific activity was at the low end of what was acceptable for antibody therapy, ranging from about 5 to $10 \mathrm{Ci}(185-370 \mathrm{~GB} \mathrm{q})$ per $\mathrm{mg}$ of $\mathrm{Cu}$ at $\mathrm{EOB}$. W ith the construction of a new target station at the IPF at LANL in 2004, the beam intensity and production have improved, but year-round availability still cannot be assured. Recent studies at BNL have tried to determine the causes of the low specific activity. ${ }^{24}$ Exhaustive assays of all the reagents used in processing determined that these contribute only approximately $0.3 \mu \mathrm{g}$ of $\mathrm{Cu}$. Addition of the $\mathrm{ZnO}$ target to these blank experiments contributed only another $1.4 \mu \mathrm{g}$ of $\mathrm{Cu}$. This compares with the $25 \mu \mathrm{g}$ of $\mathrm{Cu}$ typically measured in a batch of 80 to $380(\sim 3-14 \mathrm{~GB} \mathrm{q})$ of Copper-67. This result implies that most of the stable $\mathrm{Cu}$ found in each batch is produced directly by proton nuclear reactions on $\mathrm{Zn}$, an often forgotten process. To investigate this hypothesis further, theoretical cal culations of stable $\mathrm{Cu}$ isotopes were attempted using the well-known nuclear radiation transport code $M C N P X$. The predicted direct production of stable Cu-63 was approximately $11 \mu \mathrm{g}$, and $1 \mu \mathrm{g}$ of stable Cu-65, for every $200 \mathrm{mCi}(\sim 7.4 \mathrm{GBq})$ of $\mathrm{Cu}-67$ produced. Therefore, this route is the major source of the reduction in specific activity and will be very difficult to remove. B ecause $\mathrm{Cu}-63$ is likely produced by the ${ }^{64} \mathrm{Zn}(\mathrm{p}$, $2 p)$ and ${ }^{66} Z n(p, 3 p)$ reactions, use of a highly enriched $Z n$ 68 target containing minimal Zn-64, 66 may suppress the Cu-63 production. Recent accurate cross-section measurements on the ${ }^{68} \mathrm{Zn}(p, 2 p){ }^{67} \mathrm{Cu}$ reaction performed radiochemically over the energy range of 30 to $70 \mathrm{M} \mathrm{eV}$ showed that the yield of Cu-67 is fairly high. ${ }^{24}$ Unfortunately, $\mathrm{Zn}$-68 is rather expensive. Also, recycling the target material is considered difficult because of the unavoidable coproduction of long-lived Zn-65 in the target, unless the proton energy is kept around $70 \mathrm{M} \mathrm{eV}$. To try to resolve these issues, BNL has recently been engaged in further research to develop the production of $\mathrm{Cu}-67$ using high energy proton irradiation of enriched $\mathrm{Zn}-68$ targets, followed by selective chemical separation of the pure product. ${ }^{24} \mathrm{~A}$ number of specific challenges were addressed: (i) Development of very thick electroplated Zn-68 disks as targets, (ii) development of recovery/reuse technique of this expensive material after radiochemical processing, (iii) devel opment of a target capsule that can be sealed and then opened remotely in a hot cell, (iv) development of a rapid highly selective chemical separation process for $\mathrm{Cu}-67$ and (v) performing irradiations and measurements of product radiopurity, chemical purity and labeling efficiency. This research has allowed the prospect for the production capability for $\mathrm{Cu}$-67, using a high beam-current accelerator or cyclotron, in sufficiently large quantities and with a greater than five times of the previously obtained specific activity, to support clinical trials. ${ }^{24}$

\section{Yttrium-86}

The popular beta-emitter therapeutic isotope $Y-90$, which is part of the Food and Drug Administration-approved radioimmunotherapy agent Zevalin (Spectrum Pharmaceuticals, Inc, Henderson, NV), has no imageable gamma photon in its emission. However, $Y-86$, a positron emitter $\left(E \beta^{-}=660 \mathrm{keV}, 33 \%\right.$ ) with a $\mathrm{t}^{1} / 2$ of 14.74 hours, could be a good choice as a surrogate pretherapy PET imaging congener for $Y-90^{2-5}$ for various $Y-90$ based therapeutic radiopharmaceuticals including Zevalin. A lthough there are several high energy gamma particles in its emission ( $E \gamma$, $\mathrm{keV}: 1076.6,82.5 \% ; 627.7,32.6 \%$ and many others), which contribute to increased patient dose with no benefit, for cancer patients, who are candidates for radioimmunotherapy, the imaging dose would generally not be considered as a major issue of concern.

The possible production routes for $Y-86$ that have been considered are as follows: ${ }^{86} \mathrm{Sr}(\mathrm{p}, \mathrm{n})^{86} \mathrm{Y}, \mathrm{Ep}=14.5 \rightarrow 11.0$ $\mathrm{M} \mathrm{eV} ;{ }^{\text {natRb }}(3 \mathrm{He}, \mathrm{xn}), \mathrm{E}^{3} \mathrm{He}=24 \rightarrow 12 \mathrm{M} \mathrm{eV} ;{ }^{88} \mathrm{Sr}(\mathrm{p}, 3 \mathrm{n})^{86} \mathrm{Y}$, 
$\mathrm{Ep}=45 \rightarrow 37 \mathrm{MeV}$; and ${ }^{90} \mathrm{Zr}(\mathrm{p}, 2 \mathrm{p} 3 \mathrm{n}){ }^{86} \mathrm{Y}, \mathrm{Ep}=40 \rightarrow 30$ $\mathrm{M} \mathrm{eV},{ }^{1,3-5}$ Out of these, it seems that the best method is the ${ }^{86} \mathrm{Sr}(\mathrm{p}, \mathrm{n})^{86} \mathrm{Y}$ reaction, but it requires enriched ${ }^{86} \mathrm{Sr}$, which is rather expensive, and economy requires its recovery and reuse. ${ }^{5,13,14}$ Recovered Sr-86 will contain radioactive Sr- 85 after first irradiation if the proton energy is more than $14 \mathrm{M} \mathrm{eV}$, which would mean that hot cell target assembly will be required. At BNL, we have designed such a target, both halves of which are aluminum for better conductivity, head screws are large enough for remote manipulator handling and silver-coated stainless steel C-rings are used to provide adequate seals. ${ }^{14}$ Such a target design was successful ly irradiated in the B LIP without any leakage and can be opened and sealed in a hot cell.

Modification to increase active area in beam may increase production levels but will require more enriched Sr-86 to be used. However, if really a low energy of $14 \mathrm{M} \mathrm{eV}$ is used, the amount of target material needed is not high. Targets of both natural $\mathrm{SrCl}_{2}$ and enriched $\mathrm{SrCl}_{2}$ were irradiated yielding $10-13 \mathrm{mCi} / \mu \mathrm{A} h$ of $\mathrm{Y}-86$, giving an $\mathrm{EOB}$ batch yield of $\sim 1,000 \mathrm{mCi}$ in 1 hour, which is quite high. ${ }^{14}$ Chemical yields of $Y-86$ ranged from 82 to $93 \%$, and a further improvement is desirable. For labeling purposes, this chemical purity allowed for a labeling yield of $84 \%$, and this needs to be improved further as well. The level of a major radionuclidic impurity, Y - $87 \mathrm{~m}$, was a disappointing 34 to $55 \%$. The low energy route on enriched Sr-86, which has previously been used ${ }^{4,5}$ has allowed for better material and is now being pursued at BNL for larger-scale production. At BLIP, our first irradiation gave very low yield because the beam spot was larger than the target area. Also, the lowest tunable beam energy at the BLIP is $65.5 \mathrm{M} \mathrm{eV}$, but the nuclear reaction cross-section peak is at $\sim 14.5 \mathrm{M} \mathrm{eV}$. The choice of degraders seems to have resulted in too high a target entrance energy. BLIP is not an ideal facility for this low energy reaction, but we carried out these investigations mainly to produce some material to develop a better and quicker radiochemical processing methodology that was short enough to allow for same-day irradiation and shipment, which has recently been accomplished. ${ }^{14}$

\section{ALPHA, AUGER AND CONVERSION ELECTRON EMITTERS}

\section{Alpha Emitters}

As mentioned earlier, targeted al pha radiation therapy can be a very potent treatment of cancer. ${ }^{25}$ Due to comparatively short range of al pha particles in tissue and their high LET nature, radiation damage is mainly confined to targeted cells. The radiation burden to the surrounding healthy tissues is low when compared to beta emitters. By facilitating an efficient delivery of alpha-emitting isotope it is possible to achieve a very effective treatment regimen for the types of cancer where microscopic and small volume tumors are present. The effectiveness of al pha radioimmunotherapy has been confirmed in clinical and preclinical trials. ${ }^{26,27}$

A number of alpha emitting radioisotopes have been proposed as possible candidates. A mong those are A t-211, $\mathrm{Bi}-212, \mathrm{Bi}-213, \mathrm{~A} \mathrm{C}-225, \mathrm{~Pb}-212, \mathrm{Ra}-223, \mathrm{~Tb}-149$ and $\mathrm{Fm}-255$. Some of them (Bi-212, Bi-213, A c-225, Pb-212, $\mathrm{Ra}$-223) are produced from reactor irradiations, incorporated on generators and subsequently eluted. How ever, most of the clinical studies have been inhibited by a very limited supply of al pha-emitting isotopes, especially those that have theragnostic properties, for example, astatine-211, ${ }^{213} \mathrm{Bi}$, radium-223 $(223 \mathrm{R} \mathrm{a})$ and ${ }^{225} \mathrm{Ac}$. Three of these $\left(213 \mathrm{Bi},{ }^{225} \mathrm{~A} \mathrm{C}\right.$ and $223 \mathrm{Ra}$ ) are presently produced from reactor neutron irradiations, incorporated on generators and subsequently eluted. Their parent nuclides are often fissile materials and require special safeguard requirements due to nonproliferation concerns. On the other hand, production of At-211, Tb-149 and $\mathrm{Fm}-255$ require alpha beam (At-211), $600 \mathrm{M} \mathrm{eV}$ protons (Tb-149) or neutron irradiation of Curium ( $F m-255)$. Only a very few facilities in the world have such capabilities, and most of these because of their other primary missions are not generally available for isotope production. ${ }^{1}$

\section{Astatine-211}

A statine-211 ( $\mathrm{t}^{1} \frac{1}{2}=7.2$ hours) decays through two paths, each emitting an al pha particle. The mean al pha energy is a potent $6.8 \mathrm{M} \mathrm{eV}$. It is produced by the ${ }^{209} \mathrm{Bi}(\alpha, 2 \mathrm{n})$ reaction and typically separated from the target by dry distillation into a chloroform solution. ${ }^{28,29} \mathrm{~A}$ difficulty in this process is that the cyclotron energy must be carefully controlled to minimize the coproduction of astatine-210. This isotope $(\mathrm{t} 1 / 2=8.1$ hours) decays to Po- $210(\mathrm{t} 1 / 2=138 \mathrm{~d})$ which is an al pha particle emitting bone seeker in vivo and could cause considerable hematological toxicity. The half-life of A t-211 is relatively long compared to the other al pha emitters thus, allowing time for chemistry of labeling and use for molecular carriers with slower tumor uptake. However, it is more easily catabolized and shed after cell internalization of the labeled antibody/antigen complex than the metallic alpha emitters. ${ }^{30}$ The main problem that inhibits clinical trials with this isotope is the relatively low nuclear yield and very limited number of cyclotrons capable of producing astatine-211. This situation may be somewhat improved in the coming years when the A RRONAX cyclotron in Nantes, France, as expected, goes into routine operations in early 2013. ${ }^{31}$ 


\section{Actinium-225/B ismuth-213 System}

Targeted alpha radiation therapy with alpha emitters Ac-225 and Bi-213, as is the case with astatine-211 (vide supra), is also a very promising treatment of cancer. ${ }^{25}$ If selective efficient delivery of these alpha-emitting isotopes to tumor cells is achieved, they can become very effective for the treatment of the types of cancer where microscopic and small volume tumors are present. The effectiveness of alpha radioimmunotherapy using these isotopes has already shown promise in preclinical and clinical trials. ${ }^{26,27}$ The results of the only human clinical trial involving an al pha-emitting isotope have demonstrated feasibility and antileukemic effects of Bi-213-H uM 195, a humanized anti-CD33 mA b, specifically designed to target myeloid leukemia cells. In this study, 78 to $93 \%$ of the subjects showed reduction in circulating and bone marrow blasts. ${ }^{28}$ A clinically approved A c-225/B i-213 generator capable of producing 25 to $100 \mathrm{mCi}$ of $\mathrm{Bi}-213$, suitable for antibody labeling, was developed ${ }^{32}$ and continues to be improved upon. The antibodies and peptides labeled with the generated $\mathrm{Bi}-213$ have successfully been used in numerous preclinical and clinical trials..$^{26,27,32,33} \mathrm{As}$ mentioned above, most of the clinical studies have been inhibited by a very limited supply of these and other alphaemitting isotopes, especially those that have theragnostic properties, for example, At-211, Bi-213, Ra-223 and Ac-225.

The in vivo use of targeted NCA Ac-225, in its own right, has received a great deal of attention as well. ${ }^{34,35}$ B ecause of its ability to produce 4 al pha-emitting daughters, its overall potency to destroy cells is higher. The isotope has been referred to as an in vivo alpha particle nanogenerator because its power proliferates beyond the size of the atom. ${ }^{35}$ In addition, the applications of Ac-225 were further extended to encapsulation in liposomes ${ }^{36}$ and metallofullerenes. ${ }^{37} \mathrm{At}$ the M emorial Sloan-K ettering Cancer Center, a clinical trial for radioimmunotherapy of acute myeloid leukemia with both Bi-213 and A C-225 has recently been carried out. ${ }^{38} \mathrm{~A} s$ mentioned earlier in the text, A c-225 has been used for radioimmunotherapy both as a potent alpha emitter attached to an antibody and as a generator for the daughter al pha emitter Bi-213 ( $t 1212=45.7$ minutes). The decay of $\mathrm{B} \mathrm{i-213}$ is accompanied by emission of $440.45 \mathrm{keV} \quad(I=25.9 \%)$ gamma photon, which allows SPECT imaging to study pretherapy biodistribution, pharmacokinetics and dosimetry of the labeled radiopharmaceuticals. The current availability of Ac-225 is very limited and insufficient to support ongoing and proposed clinical trials. Currently, there are two suppliers of A c-225. One is the US Department of Energy's ORNL and the other is the Institute for Transuranium Elements in K arlsruhe, Germany. B oth suppliers obtain thorium-229 from uranium-233 that was produced as part of US molten salt breeder reactor program. The current stock of purified Th-229 at OR NL is $150-\mathrm{mCi}$. In an 8-week period, about $100 \mathrm{mCi}$ of Ac-225 grows in from that supply, separated and provided for clinical trials. Because Th-229 decays to A c-225 through intermediate daughter Ra-225, Ra can be isolated to provide additional quantities (up to $20 \mathrm{mCi}$ ) of A c-225. ${ }^{39-41}$ Similarly, the Institute of Transuranium Elements can separate $43.2 \mathrm{mCi}$ of Ra-225 and $39.4 \mathrm{mCi}$ of A c-225 from their stock. ${ }^{40}$ It is widely acknowledged that the anticipated growth in demand for Ac-225 will soon exceed the levels extractable from the available uranium233. ${ }^{39}$

A t BNL, our intent is to carry out future investigations in an effort to increase the supply of A c-225. This would involve using the high energy proton spallation reaction ${ }^{232} \mathrm{Th}(\mathrm{p}, 2 \mathrm{p} 6 \mathrm{n}){ }^{225} \mathrm{Ac}$ on natural Thorium. This method has recently been studied and developed at other places, in particular, at the Institute of Nuclear Research (INR) in Troitsk, Russia, using accelerated protons at energies between 90 and $145 \mathrm{MeV}$ in their $160-\mathrm{M} \mathrm{eV}$ proton accelerator. ${ }^{41}$ This investigation has pointed out that the yield of Ac-225 increases monotonically with the proton energy. Therefore, the BLIP at BNL (200 M eV) would be capable of producing al most twice as much with an incident energy on the target of $192 \mathrm{M} \mathrm{eV}$, with $110 \mu \mathrm{A}$ beam intensity. The expected outcome of the BNL effort would be the method for A c-225 production with quality (radionuclidic and chemical purity) suitable for applications both as a radiotherapeutic agent (A c-225) and as a generator of $\mathrm{Bi}-213$ (theragnostic use). The proposed work will involve development of an optimized Th-232 target for irradiation, development of the chemical procedure for dissolution and processing of irradiated target to selectively separate A c-225, and carrying out preliminary labeling studies of conventional targeting molecules with A c-225/ $\mathrm{Bi}-213$ to demonstrate the efficacy of the final purified radioisotope(s) for the eventual protein/antibody labeling applications.

At $B N L$, the method could potentially yield Curie amounts of A C-225 in a 10-day irradiation period at the BLIP. The produced A c-225 can be used for radioimmunotherapy as well as for generation of $\mathrm{Bi}-213$ in a quality suitable for clinical trials. Shorter-lived radioisotopes A c-228, 226, 224 will be coproduced in quantities comparable with those of A c-225, but the activities of these isotopes will saturate out during the 10-day irradiation. The radionuclidic purity of the Ac-225 can be improved by 
allowing a cool-off period for the target. Ten days (one $t^{1} 1 / 2$ of $\left.A c-225\right)$ after $E O B$, the coproduced $A c$ radionuclides will comprise $1 \%$ of the activity of A c-225. A mong these, A c-227, because of its 21.77-year half-life, is the only radioimpurity that might be of some concern as far as noninvasive imaging is concerned but, in principle, of less concern for theragnostic use. However, this issue would require further investigation and additional studies.

Small quantities of A c-225 can also be prepared by the reaction ${ }^{226} \mathrm{R} a(p, 2 n)^{225} \mathrm{~A}$ c over an energy range of 13 to 20 $\mathrm{M} \mathrm{eV} .{ }^{42}$ The cross-section for this reaction is calculated to reach a peak of $700 \mathrm{mb}$ at $16 \mathrm{M} \mathrm{eV}$ but total yield is limited by the small energy range (and target thickness) where this reaction is favorable. Similarly the photonuclear reaction ${ }^{226} \mathrm{Ra}(\gamma, \mathrm{n}){ }^{225} \mathrm{Ra}$ ( $\mathrm{t}^{\mathrm{t}} \mathrm{2}=14.9$ days) follow ed by beta decay to A c-225 is feasible but requires an extremely large $R$ a target $(\sim 40 \mathrm{~g})$ that represents radiological safety issues and availability concerns.

Thus, A c-225, when produced by the BNL method, could substantially add to the very limited present supply of this promising alpha emitter. A ccording to experimental and theoretical extrapolations, and assuming certain target dimensions, radiochemical processing losses, and so forth, the projected yields from a 10-day irradiation at the 5 high energy accelerators in the world are estimated (from the studies at INR) to be as follows (in Curies; experimental, and theoretical values within parentheses): BLIP at BNL, 3.1 (4.9); INR in Russia, 2.6 (4.1); IPF at LA NL, 0.7 (1.3); Tri-U niversity Meson Facility (TRIUMF) in Canada, 0.5 (0.7); and A rronax in France, 0.2 (0.7), giving a total of $\sim 7$ (11) curies. $^{41}$ This would allow detailed preclinical and clinical studies to determine the therapeutic potential of A c-225 itself as well as of the theragnostic daughter $\mathrm{Bi}-213 . \mathrm{M}$ any of the presently available bifunctional chelating agents as well as those based on cyclohexylethylenediamine tetraacetic acid (CDTA) and 1,4,7,10tetraazacyclo-dodecane-1,4,7,10-tetraacetic acid (DOTA) derivatives, developed earlier at BNL ${ }^{43,44}$ should allow linking A C-225 and Bi-213 with protein bifunctional chelating agent conjugates that will have high in vivo thermodynamic and kinetic stability. It would, of course, serve as a generator of $\mathrm{B}-213$ similarly to $\mathrm{Ac}-225$, produced by the decay from Th-229.

\section{Auger and Conversion Electron Emitters}

The production of metastable nuclei, such as conversion electron emitter Sn-117m and Auger electron emitter Pt$195 \mathrm{~m}$ via neutron radiative capture reactions is characterized by small neutron cross-sections and, hence, low production rates. M etastable nuclei typically have excitation energies on the order of $100 \mathrm{keV}$, and large differences in angular momentum from ground states (most metastable nuclei have high angular momentum). A $n$ al ternative route for producing these types of metastable nuclei is through neutron inelastic scattering where the cross-section of the ${ }^{A} Z\left(n, n^{\prime}\right)^{A m} Z$ reaction is, in some cases, substantially higher than the crosssection for the ${ }^{(A-1)} Z(n, \gamma)^{A m} Z$ route. A s has been shown for the case of $S n-117 m^{45}$ the magnitude of gain in the crosssection may compensate for the relatively lower fast neutron flux from a well-moderated fission spectrum. $N$ ote that the excitation energy of metastable nuclei will represent the threshold for inelastic scattering. Large research reactors, such as HFIR at ORNL, and HFBR (now closed down) in the U nited States, and at the R esearch Institute of A tomic Reactors (RIAR) in Dimitrovgrad, Russia, with significant epithermal and fast neutron fluxes, have been well suited for these types of reactions.

A systematic study of the production of $\mathrm{Sn}-117 \mathrm{~m}$, and Pt-195m in the hydraulic tube facility of the HFIR was reported. ${ }^{46}$ In all three cases, the yields from the $\left[n, n^{\prime}\right]$ reactions were higher than those obtained from the $[n, \gamma]$ reactions. The relative gains in the specific activity of the unfiltered (no Cd filter) targets were 1.4, for Pt-195m, and 3.3 for $5 n-117 \mathrm{~m}$. The excitation energies for $5 \mathrm{n}-117 \mathrm{~m}$ and Pt-195m are 314.6 and $259.2 \mathrm{keV}$ respectively. Since, the thresholds for these inelastic scattering reactions are well above the cadmium cutoff, $\mathrm{Cd}$ filters did not have any effect on the yield of these reactions. The corresponding crosssections for the inelastic neutron scattering reactions for the production of Sn-117m, and Pt-195m are $222 \pm 16$, and $287 \pm 20 \mathrm{mb}$ respectively. A value of $176 \pm 14 \mathrm{mb}$ for the cross-section of Sn-117[n, n']Sn-117m reaction obtained at HFBR was reported earlier. ${ }^{45}$

\section{Conversion Electron E mitter Tin-117m}

The most common method for $5 \mathrm{n}-117 \mathrm{~m}$ production is based on irradiation of tin with neutrons using the ${ }^{117} \mathrm{Sn}(\mathrm{n}$, $n \gamma)^{117 m} S n$ reaction. ${ }^{45} \mathrm{H}$ owever, since this reactor production method is based on the inelastic neutron scattering reaction using enriched $\mathrm{Sn-117}$ as a target, it results in $\mathrm{Sn-117m}$ with a low specific activity of about $\leq 20 \mathrm{Ci} / \mathrm{g}^{47}$ Stannic complexes with $S n-117 m$ of such specific activity, particularly $5 n-117 m^{4+}$-DTPA, effectively reduce pain from bone metastases without adverse reactions related to bone marrow, as demonstrated by the results presented in Tables 4 and $5 .{ }^{48} \mathrm{H}$ owever, such low specific activity does not allow scaling up the therapeutic doses for treating bone metastases. A lso it is not acceptable for radioimmunotherapy and for many other applications.

A lthough it is not possible to achieve a higher than about $22 \mathrm{mCi} / \mathrm{mg}$ of specific activity in the reactor-produced tin- 
A Bridge not too Far: Personalized Medicine with the use of Theragnostic Radiopharmaceuticals

\begin{tabular}{|c|c|c|c|c|c|}
\hline \multicolumn{6}{|c|}{ Patients experiencing relief } \\
\hline $\begin{array}{l}\text { Dose group } \\
\text { (MBq/kg) }\end{array}$ & $n^{2}$ & $\begin{array}{l}\text { Complete } \\
(100 \%)\end{array}$ & $\begin{array}{l}\text { Partial } \\
(>50 \%)\end{array}$ & $\begin{array}{l}\text { None } \\
(0-50 \%)\end{array}$ & $\begin{array}{c}\text { Total response } \\
(\%)\end{array}$ \\
\hline 2.6 & 5 & 0 & 3 & 2 & $3(60)$ \\
\hline 5.3 & 9 & 3 & 4 & 2 & $7(78)$ \\
\hline 6.6 & 5 & 3 & 1 & 1 & $4(80)$ \\
\hline 8.5 & 9 & 2 & 4 & 3 & $6(67)$ \\
\hline 10.6 & 12 & 4 & 6 & 2 & $10(83)$ \\
\hline All doses & 40 & 12 & 18 & 10 & $30(75)$ \\
\hline
\end{tabular}

${ }^{1}$ Total patients $57 ; 54$ received a single dose and 3 received 2 doses each; ${ }^{2} \mathrm{~A}$ total of 40 therapeutic administrations were assessable

\begin{tabular}{|c|c|c|c|c|}
\hline \multirow[t]{2}{*}{ Radiopharmaceutical } & \multicolumn{2}{|c|}{ Dose group } & \multicolumn{2}{|c|}{ No. of patients with grade $\leq 2$ toxicity } \\
\hline & $(\mathrm{mCi} / \mathrm{Kg})$ & $\mathrm{n}$ & WBC & Platelets \\
\hline $\mathrm{Sr}-89 \mathrm{Cl}_{2}$ & $\begin{array}{l}0.154 \\
0.040\end{array}$ & $\begin{array}{r}67 \\
161\end{array}$ & $\begin{array}{l}25(37 \%) \\
48(31 \%)^{2}\end{array}$ & $41(61 \%)$ \\
\hline Re-186 HEDP & $0.500-1.143$ & 12 & $2(17 \%)$ & $3(25 \%)$ \\
\hline \multirow[t]{3}{*}{ Sm-153 EDTMP } & 1.00 & 20 & $3(15 \%)$ & $5(25 \%)$ \\
\hline & 1.50 & 4 & $3(75 \%)$ & $1(25 \%)$ \\
\hline & 3.00 & 6 & $4(100 \%)$ & $2(50 \%)$ \\
\hline \multirow{3}{*}{ Sn-117m DTPA } & 0.143 & 9 & $1(11 \%)$ & $0(0 \%)$ \\
\hline & 0.179 & 5 & $0(0 \%)$ & $0(0 \%)$ \\
\hline & 0.286 & 12 & $1(8 \%)$ & $0(0 \%)$ \\
\hline
\end{tabular}

${ }^{1}$ Using NCl criteria; ${ }^{2}$ Only hematological toxicity at grade $\geq 2$ mentioned

$117 \mathrm{~m}^{47} \mathrm{NCA}$ tin-117m can be produced by proton irradiation of antimony via nuclear reactions $(p, 2 p 3 n)$ or (p, $2 p 5 n)$ in an accelerator. ${ }^{45,49}$

NCA Sn-117m can also be produced in an accelerator via a large number of other nuclear reactions. Using the ${ }^{115 \mathrm{~m}} \mathrm{In}(\alpha, \mathrm{pn})^{117 \mathrm{~m}} \mathrm{Sn}$ reaction over the energy range of 45 to $20 \mathrm{M} \mathrm{eV}$, a relatively pure product is obtained; however, with very small yields. ${ }^{50}$ In addition, the nuclear reaction ${ }^{116} \mathrm{Cd}(\alpha, 3 n){ }^{117 m} \mathrm{Sn}$ is also very useful for the production of NCA Sn-117m. The thick target yield over the energy range $47 \rightarrow 20 \mathrm{M} \mathrm{eV}$ is about $150 \mu \mathrm{Ci} / \mu \mathrm{Ah}$. Unfortunately, the present limiting factor for the scaled up production of $5 n-117 \mathrm{~m}$ via this route is the availability and power of existing alpha accelerators and targetry. ${ }^{51}$ U sing the BLIP at BNL, we have been producing NCA Sn-117m with the natural antimony ${ }^{(\text {natSb) }}(p, x n)^{117 m} S n$ reaction over the energy range of 38 to $60 \mathrm{M} \mathrm{eV}$ for quite some time. ${ }^{45}$ This process, with a cross-section of $5 \mathrm{mb}$, was found enough to produce therapeutic quantities of $\mathrm{Sn}-117 \mathrm{~m}$ with high specific activity. The specific activity when assumed to be wholly dependent on the amount of Sn impurity in the $\mathrm{Sb}$ target was calculated to be $30,000 \mathrm{mCi} / \mathrm{mg}$ for each part per million of $\mathrm{S} n$ in the target. However, further theoretical cross-section calculations at the INR in Troitsk, Russia (vide infra) have demonstrated that the proton energy range should be much broader, perhaps 40 to $130 \mathrm{M} \mathrm{eV}$. ${ }^{49}$ The specific activity of Sn-117m depends mainly on the amount of stable tin, which is also generated during the irradiation of natural $\mathrm{Sb}$, and the specific activity can vary from 1000 to 3000 $\mathrm{mCi} / \mathrm{mg}$ at $E O B$, a range that is quite suitable for radiolabeling molecules that bind to saturable in vivo receptors.

M ore recently, the larger-scale accelerator production and availability of NCA Sn-117m with high purity and high specific activity, targets based on natural or enriched $\mathrm{Sb}$ have been developed in our collaborative research between $B N L$ and INR, along with other institutes, including the Institute for Physics and Power Engineering in Obninsk (IPPE) and Moscow State University (MSU), in the neighboring regions in Russia. ${ }^{49}$ This project was initiated under a US D epartment of Energy/N ational N uclear Security A dministration/G lobal Initiative for Proliferation Prevention (DOE/NNSA GIPP) Program in 1999 and completed in 2009. Results from this 10 -year BNL/INR collaborative study have demonstrated and fulfilled the promise for the high energy accelerator production of NCA Sn-117m in multi-C urie amounts for clinical theragnostic applications. ${ }^{49}$

Within this collaborative research program with BNL, investigations at INR dealt with the development of antimony as wells as antimony/titanium intermetallic targets suitable for the high energy production of NCA tin-117m. For irradiation with the high-intensity proton beam, targets consisting of Sb-monolith encapsulated into shells made of stainless steel or graphite were developed. ${ }^{49}$ The shells were 
filled with metallic antimony as follows. Powdered metallic antimony was inserted into the shells under inert nitrogen atmosphere, and the filled shell was heated at 645 to $660^{\circ} \mathrm{C}$. It was found that at higher temperature liquid antimony reacts with iron and can destroy the stainless steel shell during the target preparation or irradiation. G raphite target shell is more reliable since there is no noticeable reaction between graphite and antimony, and graphite has higher heat conductivity than stainless steel $[80-120 \mathrm{~W} /(\mathrm{m} \cdot \mathrm{K})$ vs $20 \mathrm{~W} /(\mathrm{m} \cdot \mathrm{K})$ at $\left.300^{\circ} \mathrm{C}\right]$, providing effective target cooling. A fter antimony melting and shrinkage, the shell was again filled with powder of antimony and heated to melt again. The target with metallic shell containing a monolith of $29 \mathrm{~g}$ metallic antimony (a cylinder $9 \mathrm{~mm}$ thick, $30 \mathrm{~mm}$ in diameter) was hermetically seal ed with a threaded plug. The graphite shell targets (plates $32 \times 76 \times 5 \mathrm{~mm}, 3 \mathrm{~mm}$ of $\mathrm{Sb}$ thick each, $19 \mathrm{~g} \mathrm{Sb}$ each) were hermetically sealed with a cover by means of high temperature radiation resistant glue and electroplated outside with nickel in order to protect graphite from reaction with water radiolysis products during irradiation. ${ }^{49}$

The irradiated $\mathrm{Sb}$-targets were chemically processed at the hot cell facility at IPPE in Obninsk. The stainless steel shell was dissolved in concentrated $\mathrm{HCl}$ while the graphite shell was opened mechanically. The freed Sb monolith was dissolved in concentrated $\mathrm{HCl}$ with gradual addition of small amount concentrated $\mathrm{HNO}_{3}$. The major amount of $\mathrm{Sb}$ (in the form $\mathrm{Sb}^{5+}$ ) was removed from the solution (10-11 M $\mathrm{HCl}$ ) by extraction with dibutyl ether. Final purification of NCA Sn-117m from the rest of Sb, coproduced Te-118, $119 \mathrm{~m}, 121 \mathrm{~m}$ and $\mathrm{In}-111,114 \mathrm{~m}$ was achieved by chromatography on $\mathrm{SiO}_{2}$ in $0.5 \mathrm{M}$ sodium citrate $\left(\mathrm{Na}_{3} \mathrm{Cit}\right)$ solution. $\mathrm{T}$ in isotopes remained adsorbed on $\mathrm{SiO}_{2}$ while $\mathrm{Sb}$ and radioisotopes of $\mathrm{Te}$ and In were washed out. Then the column was washed with $0.5 \mathrm{M} \mathrm{Na}_{3}$ Cit solution and water acidified by citric acid. Finally, tin was eluted from the column with $6 \mathrm{M} \mathrm{HCl}$. Radionuclidic purity of the final solution and the specific activity of $5 n-117 m$ in the final product were determined using appropriate counting procedures (spectral emission analysis), and through inductively coupled plasma (ICP) spectrometry. A mong other isotopes of tin coproduced with $\mathrm{Sn}-117 \mathrm{~m}, \mathrm{Sn}-113$ is the most important impurity. It has a long half-life (115 d), relatively high energy $\gamma$-rays (392 keV) and cannot be chemically separated from $\mathrm{Sn}-117 \mathrm{~m}$. But it is possible to reduce $\mathrm{Sn}-113$ impurity up to almost $1 \%$ by lowering the initial proton energy. The optimum range of between 55 and $20 \mathrm{M} \mathrm{eV}$ has been demonstrated to be most effective, although at the expense of somewhat reduced $\mathrm{Sn}-117 \mathrm{~m}$ product. $^{52}$

\section{THERAGNOSTIC STUDIES WITH Sn-117m}

Sn- $117 \mathrm{~m}\left(\mathrm{t}^{1 / 2}=14.0\right.$ days; $\left.\gamma 159 \mathrm{keV}, 86 \%\right)$ shows considerable promise as a theragnostic radionuclide due to its nuclear, physical and chemical characteristics. As mentioned earlier in this paper, it is certainly one of the best radionuclides for the development of theragnostic radiopharmaceuticals, in particular, for nuclear oncology. In contrast to most other therapeutic beta emitters, $\mathrm{Sn}-117 \mathrm{~m}$ decays via isomeric transition, with the emission of three major mono energetic conversion electrons (127, 129 and $152 \mathrm{keV}$; abundance, 65,12 and $26 \%$ respectively). These emissions with a very high LET have short discrete penetration ranges of between $0.22(127 \mathrm{keV})$ and $0.29 \mathrm{~mm}$ (152 keV) in water. Therefore, Sn-117m when selectively targeted should be effective for therapy of metastatic disease and for certain other inflammatory conditions (e.g. atherosclerotic disease), causing much reduced myelosuppression and greatly reduced dose to normal organs. ${ }^{53}$ This is schematically represented in Figure 1 as well as in Figure $2^{54}$ which shows whole-body autoradiographies performed in mice and rats after the administration of Sn$117 \mathrm{~m}\left(4^{+}\right)$-diethylenetriamine pentaacetic acid (DTPA), and the highly selective targeting and high uptake in bone by this agent, but not in bone marrow or other organs, suggesting the expected effectiveness of high-LET low energy conversion electrons to produce intense radiation dose within a very short distance without affecting normal tissues, in particular, the radiation-sensitive bone marrow. ${ }^{53}$ Figure 3 shows whole body images in a prostate cancer patient, who had developed extensive bone metastases. Scan on the left was obtained using the standard Tc-99m M DP (methylene diphosphonate) imaging agent and the one on the right consists of scans obtained using tin- $117 \mathrm{~m}\left(4^{+}\right)$ DTPA, an agent which as mentioned above has shown great promise for treatment of metastatic pain in prostate and

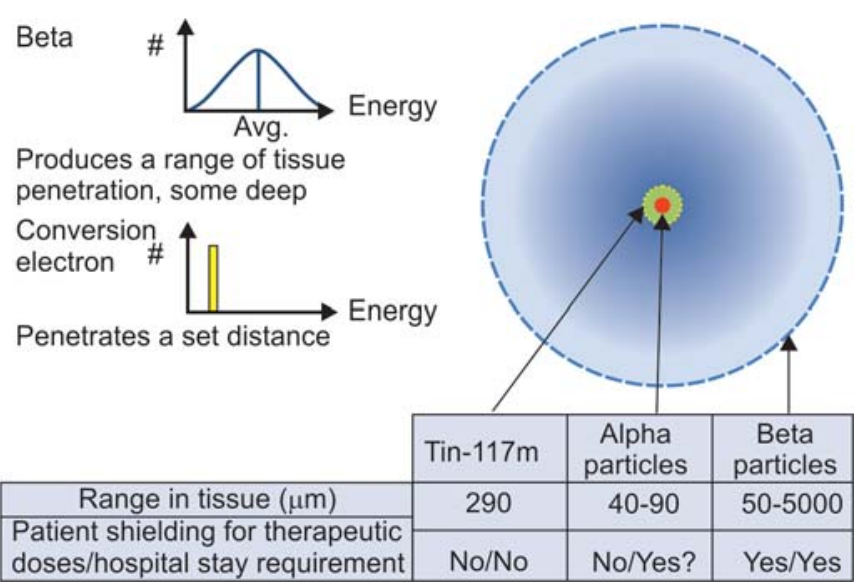

Fig. 1: A schematic comparison of energy types for therapeutic radionuclides ${ }^{1}$ 

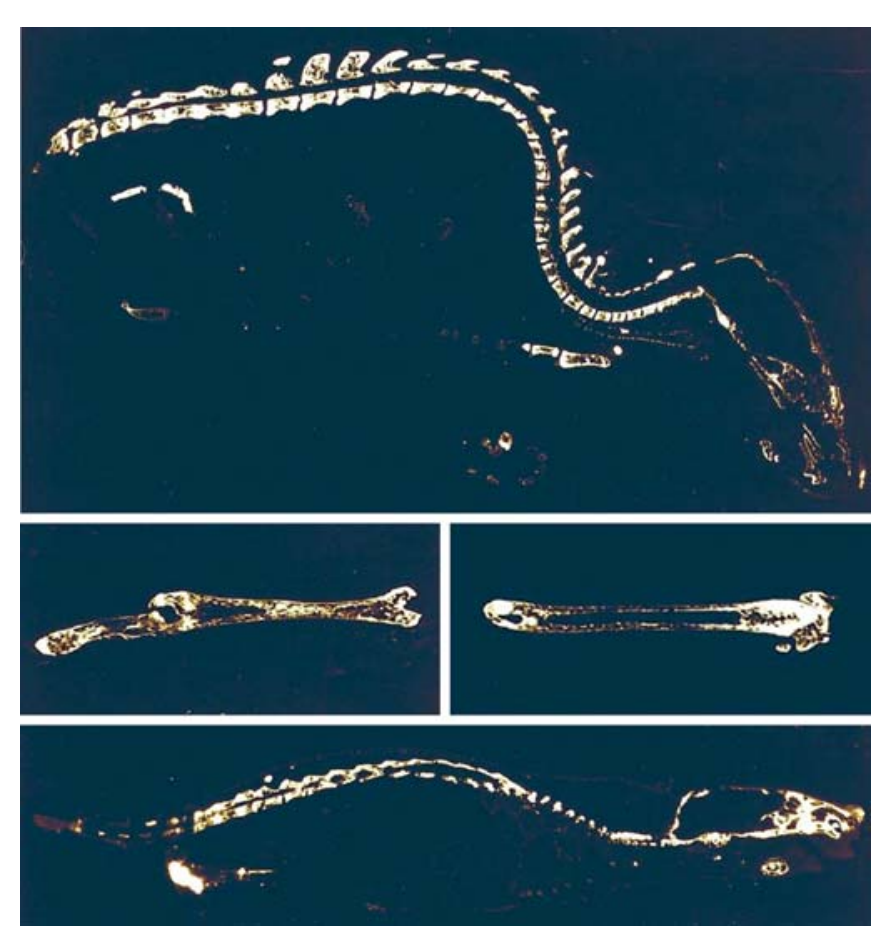

Fig. 2: Autoradiography in rats (top) and in mice (middle and bottom) demonstrates selective targeting and high uptake of tin-117m DTPA in bone and not in bone marrow or other organs ${ }^{54}$

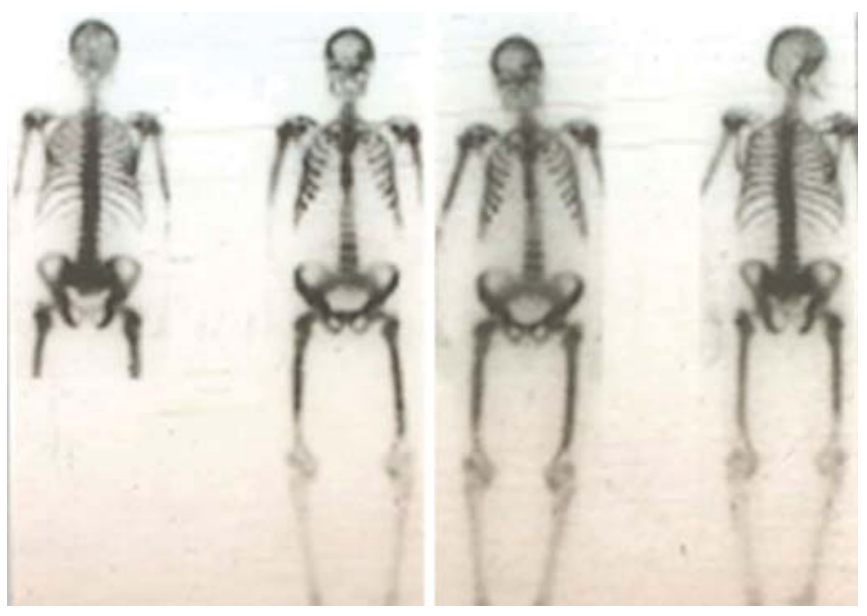

Fig. 3: Whole body images in a prostate cancer patient, who had developed extensive bone metastases. Scans on the left (posterior, anterior views) were obtained using the standard Tc-99m MDP bone imaging agent. Scans on the right are (anterior, posterior) obtained using tin-117m DTPA which is promising for treatment of metastatic bone pain and potentially of osseous metastases ${ }^{48}$

breast cancer patients. ${ }^{48}$ These two scans are almost identical, demonstrating the specificity of tin-117m DTPA localization in bone and in much higher concentration in bone metastases, in fact quantitatively even much better than the Tc-99m M DP. Figures $4 A$ and $B,{ }^{55}$ which are from an actual sample of bone tissue from a prostate cancer patient, who was treated with Sn-117m DTPA for bone pain palliation and who donated his body for research after death corroborates the same result as in Figures 2 and 3. This latter patient had died of his primary cancer 47 days after therapy with $18.6 \mathrm{mCi}(688 \mathrm{M} \mathrm{Bq})$ of Sn-117m DTPA, and the autopsy was carried out 6 hours after death. ${ }^{55}$ Figures $5 \mathrm{~A}$ and $\mathrm{B}$ displays both a picture and the bone scintigraphy of three longitudinal coronal slices ( $5 \mathrm{~mm}$ thick) of thoracolumbar vertebrae, again from the same patient as in Figures $4 \mathrm{~A}$ and $B$. The uptake of Sn-117m DTPA is both diffuse (T8) and heterogeneous (L 1). Partial involvement within a single vertebra indicates nonuniform distribution of radioactivity within the lesion, suggesting heterogeneous distribution of metastatic foci. ${ }^{55}$ Thus, the unique therapeutic emissions of Sn-117m also imply that their therapeutic effectiveness will be highly localized and should be lesionspecific and thus more effective. The use of Sn-117m DTPA is also very worth considering for an early-stage disease at which time, there would be the possibility of slowing or even stopping the progression of further metastatic lesions. M oreover, having the $159-\mathrm{keV} \gamma$ photon $(86 \%)$, which is very similar to that of technetium- $99 \mathrm{~m}, \mathrm{Sn}-117 \mathrm{~m}$ is perfect for pretherapy imaging for dosimetry and for other information in the same patient as well as for monitoring the results of treatment. ${ }^{55} \mathrm{All}$ clinical studies thus, far for bone pain palliation using Sn-117m DTPA were carried out using reactor-produced $\mathrm{Sn}-117 \mathrm{~m}$, with a specific activity ranging between 8 and $20 \mathrm{Ci} / \mathrm{g}$ of $\mathrm{Sn}$. M ore recently, several 50- to $150-\mathrm{mCi}$ samples of NCA Sn- $117 \mathrm{~m}$ produced at INR as well as at the $U$ niversity of W ashington al pha cyclotron, have successfully been used and evaluated at BNL, and in collaboration with the Saint J oseph's T ranslational Research Institute in A tlanta and at other institutions, for effectiveness for theragnostic applications in animal models..$^{56,57}$

Tin-117m, in addition to being a good therapeutic agent for cancer, also shows promise for the noninvasive molecular imaging and treatment of active atheromatous disease [vulnerable plaque (VP), also known as thin-cap fibroatheroma (TCFA)], in the coronary arteries and other areas of vasculature through the use of (i) coronary stents electroplated with Sn-117m or (ii) specific Sn-117m-labeled molecules systemically targeted to V P components.

In the U nited States, there are, on an average, about 875,000 to $1,000,000$ new heart attacks every year, and these are caused by two different types of atherosclerotic disease: Luminal calcified plaque and extraluminal active atheromatous disease leading to the formation of $\mathrm{VP}$ (Fig. 6). Vulnerable (unstable) plaque forms below the lumen in coronary artery walls, and inflammation is the main driver. VP is usually covered by a thin cap on the lumen side. When ruptured, the thin cap 'releases' highly thrombogenic material activating clotting cascade and inducing thrombosis. Approximately more than 120 substances are expressed in ruptured VP (including 


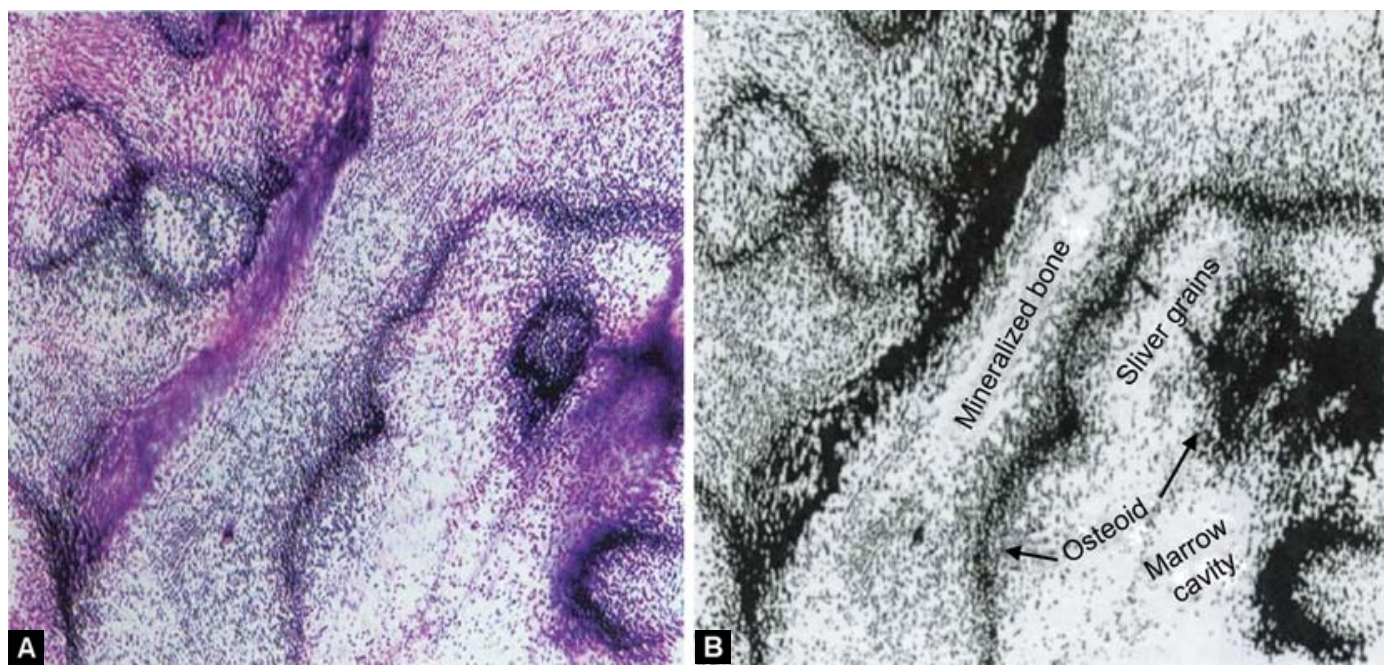

Figs 4A and B: Microautoradiographic demonstration of the deposition of Sn-117m DTPA in bone (A) and a schematic diagram (B) showing sites of localization from a sample of bone obtained following the autopsy of a patient treated with $\mathrm{Sn}-117 \mathrm{~m}$ DTPA for bone pain palliation. There is high deposition in the actively mineralizing osteoid interface. Completely mineralized bone and the bone marrow space show very low deposition. Osteoid-to-marrow ratio is $11: 1^{55}$
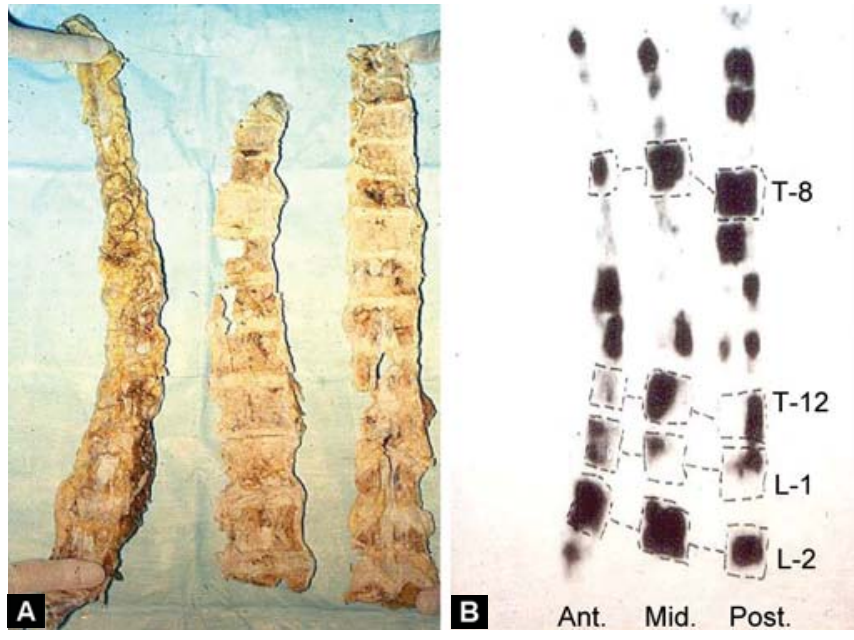

Figs $5 \mathrm{~A}$ and $\mathrm{B}$ : Photographic picture $(\mathrm{A})$ and bone scintigraphy (B) of three coronal slices (each $5 \mathrm{~mm}$ thick) of thoracolumbar vertebrae from the same patient as in Figures $4 \mathrm{~A}$ and $\mathrm{B}$. Partial involvement within a single vertebra indicates nonuniform distribution of radioactivity, within the lesion, suggesting heterogeneous distribution of metastatic foci. Note the uptake in diseased areas in various sections according to the range of the Sn-117m conversion electrons ${ }^{55}$

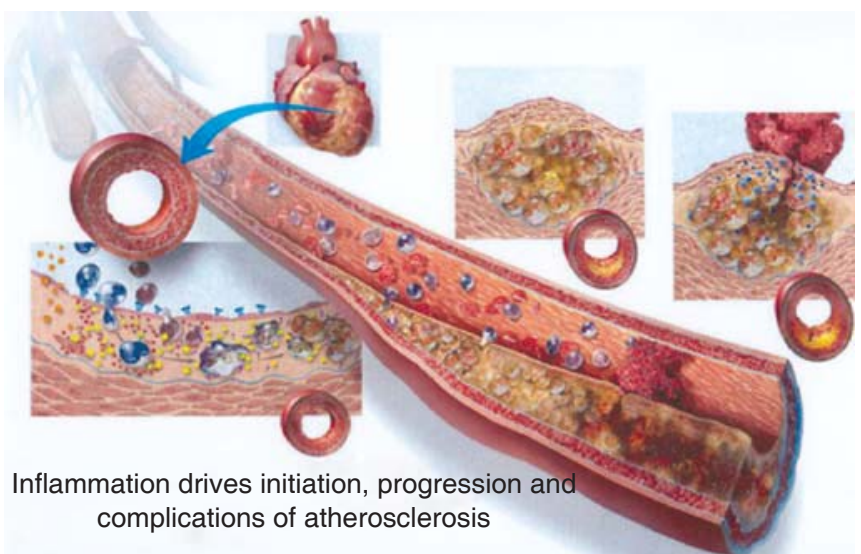

Fig. 6: A schematic representation showing the formation and positive remodeling of vulnerable plaque outside of the arterial lumen in the coronary artery walls collagen) and this rupture then results in thrombosis, which can cause unstable angina, chest pain, acute MI, sudden coronary death and stroke. The luminal calcified plaques are easily detected by existing diagnostics, and the patient has a number of treatment options. However, V P develops and models positively outside the arterial lumen (Fig. 6) and cannot be detected by noninvasive imaging techniques. Unfortunately, a majority of all significant cardiac events $(\sim 70 \%)$ leading to M I, including sudden death, are caused by the rupture of these thin-cap fibroatheroma lesions, not lumen atherosclerosis.

The properties of Sn-117m as applied to vulnerable plaques are unique and significant.

At therapeutic doses, the conversion electrons from $\mathrm{Sn}-117 \mathrm{~m}$ have been shown to reduce inflammation and, thus, are ideal for treating V $P^{\prime} s$ as their range in tissue $(\sim 300 \mu \mathrm{m})$ is approximately the same as the VP thickness in human coronary arteries. Sn-117m-labeled A nnexin effectively targets and binds to macrophage cells undergoing apoptosis, which are present in abundance in V $\mathrm{P}^{\prime} \mathrm{s}$. In relatively low doses, this agent can image the plaque using traditional SPECT gamma cameras with technetium$99 \mathrm{~m}$ collimators and imaging protocols. Because of the longer half-life of $\mathrm{Sn}-117 \mathrm{~m}$ combined with pretargeting techniques, gamma cameras can acquire images long after the nonspecifically bound tin-A nnexin has cleared the blood pool thus improving the image quality. ${ }^{58}$

A clinical trial with Sn-117m-A nnexin, begun in 2010, is currently in progress. At present, the phase Ila study (15 subjects) involves human carotid endarterectomy patients who are dosed and imaged for VP, with histology as the comparison. Further clinical trials (phase IIb and phase III) are in the planning stage. In recent studies in an 
A po-E mouse $V$ P model, in doses that appear to be imaging doses, tin-117m-A nnexin has demonstrated a significant anti-inflammatory therapeutic effect. The plaque composition showed significantly less expression of macrophages in the low, middle and high dose treatment groups as compared to the control group. In contrast, smooth muscle cell expression was greater in the middle and high dose groups as compared to the control, and in the low dose group, the difference was statistically significant between the low vs middle and high dose groups. ${ }^{59}$

B ecause inflammatory cells are more radiosensitive than other arterial wall cell types, the conversion electrons should exhibit a beneficial anti-inflammatory effect in diseased coronary arteries. Since 28 days, corresponding to two halflives of $\mathrm{Sn}-117 \mathrm{~m}$, is believed to be roughly the optimum period for neoproliferative tissue suppression, including neointimal proliferation after angioplasty and other primary interventional treatments in the coronary arteries and other vasculature, radiotherapy with $\mathrm{Sn}-117 \mathrm{~m}$ should provide highly effective treatment, with minimal collateral damage to adjacent, quiescent arterial wall cells because of its low energy conversion electron emission and short penetration in tissue. Furthermore, such limited energy delivery from a radioactive stent implant may circumvent the problem of cellular overgrowth at the implant edges, known as the 'candy wrapper' effect, which has been observed with previous forms of radioactive stents.

At BNL, a novel radioactive stent stably electroplated with $\mathrm{Sn}-117 \mathrm{~m}$ was developed as a therapeutic tool for the treatment of atherosclerotic coronary arteries. ${ }^{60} \mathrm{E}$ ffects on vessel wall inflammation from various doses of electroplated Sn-117m were studied in hyperlipidemic rabbits. Three days after stent implantation in the abdominal aorta [4 doses: 0- (cold tin), 30-, 60- and 150- $\mathrm{CC}$ Sn-117m per 15-mm stent], the rabbits were sacrificed. Immunohistochemical analysis of proliferating macrophages and smooth muscle cells demonstrated that inflammatory cells in the $\mathrm{Sn}-117 \mathrm{~m}$ stented segments were dramatically reduced in a dosedependent manner. ${ }^{56,57}$ The anti-inflammatory therapeutic effectiveness of the tin-117m-stent implants was further demonstrated in a preliminary study in pigs (24 pigs, 72 bare metal stent implants: 0 - to $400-\mu \mathrm{Ci} \mathrm{Sn}-117 \mathrm{~m}$ per 15-mm stent), which was carried out to investigate the effects on in-stent neointima formation. The electroplating process appeared benign because the response from 'cold' tin-plated stents was indistinguishable from what was observed for routinely used bare metal, 316L surgical stainless steel stents. A profound and unique radiation effect was consistently observed in the higher dose implants, which consisted of a discrete zone of dense connective tissue consolidation in the tunica adventitia, of $\sim 0.25$ to $0.30 \mathrm{~mm}$ thickness, corresponding to the anticipated tissue penetration of the $\mathrm{Sn}-117 \mathrm{~m}$ conversion electron energy. Focal suppression of in-stent neointima formation was also observed, but further study will be needed to determine, with certainty, the therapeutic potential of Sn-117melectroplated stents for prevention of in-stent restenosis. ${ }^{61}$ To summarize, tin- $117 \mathrm{~m}$ shows great promise as a means to reduce inflammatory events following stent implantation, and when delivered systemically to atherosclerotic tissue using specific targeting molecules (e.g. A nnexin-V), is effective in low doses to image and in higher doses to reduce the vulnerability for rupturing of unstable coronary artery plaques.

NCA Sn-117m is also being developed and tested for the therapy of bone metastases and for use in radioimmunotherapy. A phase I clinical trial for the imaging and treatment of bone metastases using Sn-117m DTPA in prostate cancer patients is in the planning stage for 2013.

\section{CONCLUSION}

There are a number of existing and potential future radionuclides for use as unsealed sources for targeted therapy of cancer and for other therapeutic applications in nuclear medicine. The various important therapeutic applications where radionuclide therapy would have an important role to play in, and the radionuclides best suited for that particular type of application, are summarized in Table 6. It should be noted that this listing is not meant to be exhaustive and additional radionuclides can be added based on present and future work as well as various other considerations. The substantial progress of investigations in areas, such as the treatment of cancer as well as of other inflammatory conditions, such as in bone pain palliation, radiosynovectomy, and of many other disorders that respond to radionuclide therapy, offers renewed hope and promise for the widespread use of internally administered radionuclides for a number of novel and effective therapeutic approaches.

Therapeutic nuclear medicine finally seems to be destined to find its rightful place in the 'personalized' therapy of patients with the use of a number of dual-purpose ('theragnostic') radionuclides or radionuclide pairs that are discussed and emphasized in this article. This paradigm, when properly enforced would constitute a major step forward to meet the challenges of enabling personalized medicine. Implementation of this regimen potentially creates a situation where treatments are better targeted, health systems save money by identifying therapies not likely to be effective for particular patients, and researchers have a better understanding of comparative effectiveness. 
Table 6: Choice of radionuclides for principal therapeutic ${ }^{*}$ applications $^{62}$

\begin{tabular}{|c|c|c|}
\hline Application & $\begin{array}{l}\text { Route of } \\
\text { administration }\end{array}$ & Best-suited radionuclide(s) \\
\hline \multicolumn{3}{|l|}{ 1. Tumor therapy } \\
\hline $\begin{array}{l}\text { (I) Solla tumors } \\
\text { a. Large lesions }\end{array}$ & iv & 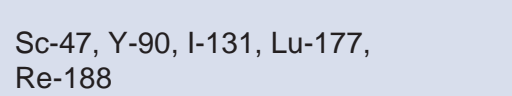 \\
\hline b. Micrometastases & $\begin{array}{l}\text { Intratumoral } \\
\text { iv }\end{array}$ & $\begin{array}{l}\text { Sc- } 47, \mathrm{Sm}-153, \mathrm{Re}-188 \\
\mathrm{Sc}-47, \mathrm{Sn}-117 \mathrm{~m}, \mathrm{Sm}-153 \text {, other } \\
\text { Auger, conversion electron, alpha and } \\
\text { short range } \beta \text {-emitters }\end{array}$ \\
\hline (ii) Leukemias, lymphomas & iv & $\begin{array}{l}\text { Sc- } 47 \text {, Cu-67, Sn-117m, I-131, alpha } \\
\text { emitters }\end{array}$ \\
\hline \multicolumn{3}{|l|}{ 2. Pain palliation } \\
\hline (i) Soft tissue & iv & Y-90, I-131, Ho-166, R e-188 \\
\hline (ii) Metastatic bone pain & iv & $\begin{array}{l}\text { Sr-89, Sn-117m, Sm-153, Lu-177, } \\
\text { Re-187, Re-188, Ra-223 }\end{array}$ \\
\hline \multicolumn{3}{|r|}{ 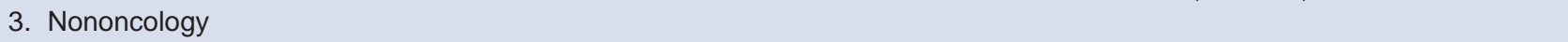 } \\
\hline (i) Synovectomy & Regional & P 32, Y-90, Sn-117m, Re-186, Er-169 \\
\hline (ii) Marrow ablation & iv & Sn-117m, Ho-166 \\
\hline (iii) Microspheres & iv & Y-90, other radio-lanthanides \\
\hline $\begin{array}{l}\text { 4. Receptor-binding tracers; cellular } \\
\text { (intranuclear) antigens }\end{array}$ & iv & $\begin{array}{l}\text { Auger, conversion electron, } \\
\text { alpha and short-range } \beta \text {-emitters }\end{array}$ \\
\hline
\end{tabular}

*The isotopes in various categories are listed in order of increasing atomic mass and not necessarily based on their degree of their therapeutic effectiveness

Theragnostic radiopharmaceuticals have the power to drive advances in personalized medicine that will offer better-targeted diagnosis and treatments. Using this approach, it would be possible to envision a future where treatments are tailored to individual patients' specific disease parameters and where imaging data could be analyzed in real-time and in advance to predict likely effectiveness of therapy and learn what would or would not work. Oncology is just the beginning; in principle, we should be able to start scientific enquiries to apply this paradigm to other complex disease states, so that the potential for theragnostic radiopharmaceutical biomarkers as a bridge to help us better detect, understand, and treat diseases like CAD, diabetes, and A Izheimer's becomes a reality. How ever, an increased and continuously reliable availability at reasonable cost of some of the best theragnostic radionuclides has remained a major issue, which must be addressed before we can successfully put this paradigm into routine clinical practice. This issue has been discussed in this paper in some detail, and the evolving new methodologies for the production of a few of the very promising theragnostic radionuclides have been covered.

It is worth emphasizing that our nuclear medicine modality is the only modality that can fulfill the dream of carrying out tailored personalized medicine by way of enabling diagnosis followed by therapy in the same patient with the same radiopharmaceutical. This would be an exciting development with a very promising future, would be of invaluable benefit to patients with cancer, cardiovascular disease, and other disorders, and may very well mark the future of the field of nuclear medicine.

\section{ACKNOWLEDGMENTS}

This work was supported by the U nited States Department of Energy, Office of Science/Office of Nuclear Physics/ Isotope Development and Production for Research and A pplications Program, and the NNSA-NA-24 GIPP Program, under Contract No. DE-A C02-98CH 10886, at B rookhaven $\mathrm{N}$ ational L aboratory. A dditional research grant support for part of this work by Clear V ascular Inc, including a Cooperative Research and Development A greement (CRADA) with BNL, is gratefully acknowledged.

\section{REFERENCES}

1. Srivastava SC. Paving the way to personalized medicine: Production of some promising theragnostic radionuclides at Brookhaven National Laboratory. Semin Nucl Med 2012;42: 151-63.

2. Srivastava SC. Theragnostic radiopharmaceuticals: The 'J anus' approach to molecular diagnosis and therapy. CME session \# 63 on N ovel radiopharmaceuticals for molecular imaging and therapy-where are we headed next? Presented at 2009 SN M A nnual M eeting, Toronto, Canada, June 15, 2009.

3. Srivastava SC. Theragnostic radiometals: Getting closer to personalized medicine. In: Mazzi $U$, et al (Eds). Technetium and other radiometals in chemistry and nuclear medicine. Padova, Italy, SG Editorial 2010;553-68.

4. Srivastava SC. Paving the way to personalized medicine: Production of some theragnostic radionuclides at B rookhaven National Laboratory. Radiochim A cta 2011;99:635-40. 
5. Herzog H, Rösch F, Stöcklin G, et al. Measurement of pharmacokinetics of yttrium-86 radiopharmaceuticals with PET and radiation dose calculation of analogous yttrium-90 radiotherapeutics. J N ucl M ed 1993;34:2222-36.

6. Srivastava SC. Radiolabel ed monoclonal antibodies for imaging and therapy. N ew Y ork: Plenum Press 1988;876.

7. Srivastava $\mathrm{SC}, \mathrm{D}$ adachova $\mathrm{E}$. R ecent advances in radionuclide therapy. Seminars in N ucl M ed 2001;31:330-41.

8. Traub-W eidinger $\mathrm{T}$, Raderer $\mathrm{M}$, U ffman $\mathrm{M}$, et al. Improved quality of life in patients treated with peptide radionuclides. World J Nucl Med 2011;10:115-21.

9. Kassis A I, A delstein SJ, Haycock C, et al. Lethality of A uger electrons from the decay of $\mathrm{Br}-77$ in the DNA of mammalian cells. Radiat Res 1982;90:362-73.

10. A delstein SJ, Kassis A I. Radiobiologic implications of the microscopic distribution of energy from radionuclides. $\mathrm{Nucl} \mathrm{M}$ ed Biol 1987;14:165-69.

11. Feinendegen LE. Biological damage from the A uger effect: Possible benefits. Radiat Environ B iophys 1975;12:85-99.

12. Szelecsenyi F, Blessing G, Q aim SM. Excitation functions of proton induced nuclear reactions on enriched ${ }^{61} \mathrm{Ni}$ and ${ }^{64} \mathrm{Ni}$ : Possibility of production of no-carrier-added ${ }^{61} \mathrm{Cu}$ and ${ }^{64} \mathrm{Cu}$ at a small cyclotron. A ppl Radiat Isotopes 1993;44:575-80.

13. Sadeghi $M, A$ boudzadeha $M, Z$ al i A, et al. R adiochemical studies relevant to $Y-86$ production via ${ }^{86} \mathrm{Sr}(p, n)^{86} Y$ for PET imaging. A ppl Radiat Isot 2009;67:7-10.

14. M edvedev D, M ausner LF, Srivastava SC. Irradiation of strontium chloride targets at proton energies above $35 \mathrm{M} \mathrm{eV}$ to produce PET radioisotope $Y$-86. Radiochim A cta 2011;99: 755-61.

15. A slam M N, Sudar $S$, Hussain $M, M$ alik $A A$, et al. Evaluation of excitation functions of ${ }^{3} \mathrm{He}$ and $\alpha$-particle induced reactions on antimony isotopes with special relevance to the production of iodine-124. A ppl Radiat I sotopes 2001;69:94-104.

16. Huclier-M arkai S, Sabatie A, K ubicek V, et al. Chemical and biological eval uation of scandium (III)-polyamino-polycarboxylate complexes as potential PET agent and radiopharmaceutical. Radiochim A cta 2011;99:653-62.

17. M einken GE, K urczak S, M ausner LF, Kolsky $K L$, Srivastava SC. Production of high specific activity Ge-68 at B rookhaven National Laboratory. J Radioanal Nucl Chemistry 2005;263:553-57.

18. M ausner LF, Kolsky KL, M ease RC, et al. Production and evaluation of Sc-47 for radioimmunotherapy. J L abelled Compds Radiopharm 1993;32:388-90.

19. Kolsky KL, J oshi V , M ausner LF, Srivastava SC. Radiochemical purification of no-carrier-added Scandium-47 for radioimmunotherapy. A ppl Radiat Isot 1998;49:1541-49.

20. M ausner LF, K olsky $K L$, J oshi $V$, Sweet MP, M einken GE, Srivastava SC. Scandium 47: A replacement for $\mathrm{Cu}-67$ in nuclear medicine therapy with beta/gamma emitters. In: Stevenson N (Eds). Isotope production and applications in the 21st Century. L ondon: W orld Scientific 2000;43-45.

21. M irzadeh S, M ausner LF, Srivastava SC. Production of nocarrier-added Cu-67. Int J Radiat A ppl Instrum Part A, A ppl Radiat I sot 1986;37:29-36.

22. DeN ardo GL, DeNardo S], Kukis DL, O'Donnell RT, et al. $M$ aximum tolerated dose of ${ }^{67} \mathrm{C} U-2 \mathrm{IT}-\mathrm{BAT}-\mathrm{L} Y \mathrm{M}-1$ for fractionated radioimmunotherapy of non-H odgkin's lymphoma: A pilot study. A nticancer Res 1998;18:2779-88.

23. DeNardo SJ, DeNardo GL, Kukis DL, et al. ${ }^{67} \mathrm{Cu}$-2IT-BAT Lym-1 pharmacokinetics, radiation dosimetry, toxicity and tumor regression in patients with lymphoma. J Nucl M ed 1999; 40:302-10.
24. M edvedev DJ, M ausner LF, M einken GE, et al. Development of large scal e production of $\mathrm{Cu}-67$ from Zn-68 at the high energy accelerator: Closing the Zn-68 cycle. Int J Appl Radiat Isot 2012;70:423-29.

25. Dadachova E. Cancer therapy with alpha-emitters labeled peptides. Semin N ucl M ed 2010;40:204-08.

26. Jurcic J G, Larson SM, Sgouros G, et al. Targeted particle immunotherapy for myeloid leukemia. Blood 2002;100:1233.

27. M iederer $M$, Henriksen $G, A$ lke $A$, et al. Preclinical evaluation of the al pha-particle generator nuclide A c-225 for somatostatin receptor radiotherapy of neuroendocrine tumors. Clin Cancer Res 2008; 14:3555.

28. Larsen RH, W ieland BW, Zalustsky M R. Evaluation of an internal cyclotron target for the production of ${ }^{211} \mathrm{~A}$ t via the ${ }^{209} \mathrm{Bi}$ (alpha, 2n)211 at reaction. A ppl Radiat Isot 1996;47: 135-43.

29. Zalutsky MR, Zhao XG, Alston KL. High-level production of alpha-particle-emitting (211)A t and preparation of (211) At-labeled antibodies for clinical use. J Nucl Med 2001;42: 1508-15.

30. Y ao Z, Garmestani K, Wong KJ, et al. Comparative cellular catabolism and retention of astatine-, bismuth-, and leadradiolabeled internalizing monoclonal antibody. J Nucl Med 2001;42:1538-44.

31. Haddad F, Barbet J, Chatal JF. The arronax project. Current Radiopharm 2011;4:186-96.

32. M cD evitt M R, Finn RD, Sgouros G, et al. An A C-225/Bi-213 generator system for therapeutic clinical applications: Construction and operation. A pplied Radiat I sot 1999;50:895.

33. N orenberg JP, K renning BJ, K onings I, et al. Bi-213- DOTA (0), Tyr(3) octreotide peptide receptor radionuclide therapy of pancreatic tumors in a preclinical animal model. Clinical Cancer Res 2006;12:897.

34. Geerlings $M W, K$ aspersen $F M$, A postolidis $C$, et al. The Feasibility of AC-225 as a source of alpha-particles in radioimmunotherapy. Nucl M ed Commun 1993;14:121.

35. $M$ iederer $M$, Scheinberg $D A, M C D$ evitt $M R$, et al. Realizing the potential of the Actinium-225 radionuclide generator in targeted alpha particle therapy applications. A dvanced Drug Delivery Reviews 2008;60:1371.

36. Sofou S, Kappel BJ , Jaggi J S, et al. Enhanced retention of the al pha-particle-emitting daughters of actinium-225 by liposome carriers. Bioconj Chem 2007;18:2061.

37. A kiyama K, Haba H, Tsukada K, et al: A metallofullerene that encapsulates A C-225. J. Radioanal Nucl Chem 2009;280:329.

38. S J urcic J G, M CD evitt M R, Pandit-Taskar N, et al. A lpha-particle immunotherapy for acute myeloid leukemia ( $A M L)$ with bismuth-213 and actinium-225. Cancer Biother Radiopharm 2006;21:40.

39. Boll RA, M alkemus D, M irzadeh S. Production of actinium225 for al pha particle mediated radioimmunotherapy. A ppl Radiat I sot 2005;62:667.

40. A postolidis $C$, M olinet $R$, Rasmussen $G$, et al. Production of A C-225 from Th-229 for targeted al pha therapy. A nal ytical $C$ hem 2005; $77: 6288$.

41. Zhuikov BL, Kalmykov SN, Ermolaev SV, et al. Production of ${ }^{225} \mathrm{~A} \mathrm{C}$ and ${ }^{223} \mathrm{R}$ a by irradiation of Th with accelerated protons. Radiochemistry 2011;53:73-80.

42. M elville $G, A$ llen $B$ J. Cyclotron and linac production of $A C$ 225. A ppl. Radiat I sot 2009;67(4):549-55.

43. M ease RC, M ausner LF, Srivastava SC. M acrocyclic polyaminocarboxylates for radiometal antibody conjugates for therapy, SPECT and PET imaging. US Patent \#5,639,879, J une 17, 1997. 
44. Sweet MP, M ease RC, Srivastava SC. Rigid bifunctional chelating agents. US Patent \#6,022,522, February 8, 2000.

45. M ausner LF, M irzadeh $S, W$ ard TE. N uclear data for production of $117 \mathrm{mSn}$ for biomedical application. In: Proceedings of the International C onference on N uclear Data for Basic and A pplied Science. Santa Fe: N ew M exico 1985 M ay;733-37.

46. M irzadeh S, Knapp FF J r, A lexander CW, M ausner LF. Evaluation of neutron inelastic scattering for radioisotope production. A ppl Radiat I sot 1997b;48:441-46.

47. Srivastava SC, Toporov Y UG, Karelin EA, V akhetov FZ, A ndreev $\mathrm{OI}$, et al. Reactor production of high-specific activity tin- $117 \mathrm{~m}$ for bone pain palliation and bone cancer therapy. J Nucl Med 2004:45:475.

48. Srivastava, $\mathrm{SC}, \mathrm{A}$ tkins $\mathrm{HL}, \mathrm{K}$ rishnamurthy $\mathrm{GT}$, et al. Treatment of metastatic bone pain with tin-117m(4+)DTPA: A phase II clinical study. Clinical Cancer Res 1998;4:61-68.

49. Ermolaev SV, Zhuikov BL, K okhanyuk V M, Srivastava SC, et al. Production of no-carrier-added Tin- $117 \mathrm{~m}$ from proton irradiated antimony. J Radioanal Chem 2009;280:319-24.

50. Qaim SM, Döhler H. Production of carrier-free $117 \mathrm{mSn}$. Int J A ppl Radiat Isot 1984;35:645-50.

51. Y amazaki T, Ewan GT. L evel and isomer systematics in even tin isotopes from Sn-108 to Sn-118 observed in $\mathrm{Cd}(\alpha, \mathrm{xn}) \mathrm{Sn}$ reactions. Nucl Phys A 1969;134:81-109.

52. Zhuikov B, Srivastava SC, Ermolaev SV, et al. Production of no-carrier-added Sn-117m at medium energy cyclotrons. Publication in Progress (2012).

53. Bishayee $S, R$ ao DV, Srivastava SC, et al. Marrow sparing effects of $5 n-117 m(4+)$ DTPA for radionuclide therapy of cancer in bone. J N ucl M ed 2000;41:2043-50.

54. Oster ZH, Som P, Srivastava SC, et al. The development and in vivo behavior of tin containing radiopharmaceuticals II: A utoradiographic and scintigraphic studies in normal animals and in animal models of bone disease. Int J Nucl Med Biol 1985;12:175-84.

55. Swailem FM, K rishnamurthy GT, Srivastava SC, et al. In vivo tissue uptake and retention of Sn-117m (4+) DTPA in a human subject with metastatic bone pain and in normal mice. Nucl M ed Biol 1998;25:279-87.

56. Li J, M ueller DW, Srivastava SC, et al. Intravascular stents electroplated with $\mathrm{Sn}-117 \mathrm{~m}$ reduce arterial wall inflammation in hyperlipidemic rabbits. A tlanta, GA : Presented at the GLS 2007 M eeting, October 3, 2007 (abstr).

57. Li J, M ueller DW, Srivastava SC, et al. Intravascular stents electroplated with ${ }^{117 m} S n$ reduce arterial wall inflammation in hyperlipidemic rabbits. Chicago, IL: Presented at the 2008 A CC A nnual M eeting, M ay, 2008 (abstr).

58. Narula, J, Srivastava S, Petrov A, et al. Evaluation of tin$117 \mathrm{~m}$ labeled $A$ nnexin $V$ for imaging atherosclerotic lesions in a hyperlipidemic rabbit model. Publication in Progress (2013).

59. Srivastava SC, Gonzales G, Narula J, Strauss HW, et al. Development and evaluation of tin-117m labeled A nnexin for the imaging and treatment of vulnerable plaques. Publication in Progress (2013).

60. Srivastava SC, Gonzales G, A dzic R, M einken GE. M ethod of el ectroplating a conversion el ectron emitting source on implant. US Patent A pplication Serial No 11/758,914, Dec 22, 2011; Publication in Progress (2013).

61. Srivastava SC, Strauss HW, Narula J, et al. Theragnostic potential of $\mathrm{Sn}-117 \mathrm{~m}$ for the molecular targeting and therapy of vulnerable plaque. Publication in Progress (2013).

62. Srivastava SC. Therapeutic radionuclides: Making the right choice. In: M ather SJ (Eds). Current directions in radiopharmaceutical research and devel opment. Dordrecht, The N etherlands: K luwer A cademic Publishers 1996;63-79.

\section{ABOUT THE AUTHOR}

\section{Suresh C Srivastava}

Senior M edical Scientist and Head, M edical Isotope Research and Production Program, Collider-A ccelerator Department, B uilding 801 B rookhaven N ational L aboratory, U pton, N ew Y ork 11973; R esearch Professor of Radiology, Stony B rook University M edical Center, Stony Brook, NY , USA, e-mail: suresh@bnl.gov 